\title{
The Ustilago maydis Forkhead Transcription Factor Fox1 Is Involved in the Regulation of Genes Required for the Attenuation of Plant Defenses During Pathogenic Development
}

\author{
Alexander Zahiri,, ${ }^{1}$ Kai Heimel, ${ }^{1}$ Ramon Wahl, ${ }^{1}$ Magnus Rath, ${ }^{2}$ and Jörg Kämper ${ }^{1}$ \\ ${ }^{1}$ Karlsruhe Institute of Technology, Institute for Applied Biosciences, Department of Genetics, D-76187 Karlsruhe, Germany, \\ and MPI for terrestrial Microbiology, Department for Organismic Interactions, Marburg, 35043, Germany; ${ }^{2}$ Philipps-University \\ Marburg, Department for Systematic Botany and Mycology, Marburg, D-35032, Germany
}

Submitted 24 March 2009. Accepted 7 May 2010.

Ustilago maydis is a plant-pathogenic fungus that establishes a biotrophic relationship with its host plant, Zea mays. The pathogenic stage of $U$. maydis is initiated by the fusion of two haploid cells, resulting in the formation of a dikaryotic hypha that invades the plant cell. The switch from saprophytic, yeast-like cells to the biotrophic hyphae requires the complex regulation of a multitude of biological processes to constitute the compatible host-fungus interaction. Transcriptional regulators involved in the establishment of the infectious dikaryon and penetration of the host tissue have been identified; however, regulators required during the post-penetration stages remained to be elucidated. In this study, we report the identification of a $U$. maydis forkhead transcription factor, Fox1, which is exclusively expressed during biotrophic development. Deletion of fox 1 results in reduced virulence and impaired tumor development. The $\Delta f o x \boldsymbol{l}$ hyphae induce the accumulation of $\mathrm{H}_{2} \mathrm{O}_{2}$ in and around infected cells and a maize defense response phenotypically represented by the encasement of proliferating hyphae in a cellulose-containing matrix. The phenotype can be attributed to the fox 1 -dependent deregulation of several effector genes that are linked to pathogenic development and host defense suppression.

\section{A. Zahiri and K. Heimel contributed equally to this work}

Current address for K. Heimel and J. Kämper: Karlsruhe Institute of Technology, Institute for Applied Biosciences, Department of Genetics, D-76187 Karlsruhe, Germany.

Current address for R. Wahl: Novartis Pharma AG, CH-4057 Basel, Switzerland.

Sequence data from this article can be found in the National Center for Biotechnology Information (NCBI) database under accession numbers XP_757670 (U. maydis foxl, conserved hypothetical protein; um01523), XP_759193 (U. maydis, hypothetical protein; um03046), XP_760402 (U. maydis, hypothetical protein; um12258), and XP_761174 (U. maydis, hypothetical protein; um05027) of the U. maydis 521 genome sequence. DNA microarray data was submitted to the NCBI Gene Expression Omnibus database under accession numbers GSE19591 and GSE19559.

Corresponding author: Jörg Kämper; Telephone: +49-721-608-5670; Fax: +49-721-608-4509; E-mail: joerg.kaemper@kit.edu

* The $e$-Xtra logo stands for "electronic extra" and indicates that seven supplementary figures and four supplementary tables are published online.
Ustilago maydis is the causal agent of corn smut disease and serves as a well-established model organism for the study of host-pathogen interactions. U. maydis belongs to the group of biotrophic fungi that require living host tissue for proliferation. During its saprophytic phase, haploid, yeast-like cells, called sporidia, grow by budding. The biotrophic phase is initiated by fusion of two compatible sporidia, which leads to formation of the filamentous dikaryon (Banuett 1992). Initially, only the elongated tip cell is filled with cytoplasm, while the older part of the hyphae consists of heavily vacuolated compartments; the cell division is stalled until the fungus has entered its host plant. Penetration of the plant cuticle by the dikaryotic hyphae is facilitated through appressoria, specialized infection structures that are involved in softening the plant cell wall (Doehlemann et al. 2008b). During penetration, the host plasma membrane invaginates and surrounds the invading hypha, which establishes a narrow contact zone between hyphae and the plant cell (Bauer et al. 1997). Once inside the host, the fungal hyphae traverse the plant cells; however, there is no apparent host defense response, and plant cells remain alive until late in the infection process. Recently, we have demonstrated that $U$. maydis hyphae are recognized by the plant early during the infection process. However, many of the plant defense genes that respond early to the fungal infection are downregulated at later time points (Doehlemann et al. 2008a). In addition, plant genes associated with suppression of cell death are upregulated during progression of infection. Obviously, the fungus has to overcome the initial plant defense response as a prerequisite for a successful establishment of the biotrophic interaction (Doehlemann et al. 2008a). It is generally accepted that effector proteins secreted by pathogens interfere with the defense pathways of the host and trigger susceptibility. The $U$. maydis genome harbors a plethora of genes encoding for such potential effector proteins, many of which are organized in gene clusters specifically induced in planta (Kämper et al. 2006; Müller et al. 2008). Five of the gene clusters are required for biotrophic development (Kämper et al. 2006) and, in addition, the secreted effector Pep1 has been shown to be compulsory for penetration of epidermal cells (Doehlemann et al. 2009). spepl mutants induce necrotic regions and the accumulation of $\mathrm{H}_{2} \mathrm{O}_{2}$ at attempted penetration sites (Doehlemann et al. 2009), highlighting the protein's function in the suppression of plant defenses. However, which and how many of the individual genes within the clusters are required for biotrophic growth, and how the different effectors exert their function, is currently unknown. 
The master regulator for the establishment of the biotrophic phase is the heterodimeric $\mathrm{bE} / \mathrm{bW}$ homeodomain transcription factor, which is encoded by the $b$-mating-type locus. The $\mathrm{bE} / \mathrm{bW}$ heterodimer is set on top of a regulatory cascade that triggers and coordinates the different processes required for the dimorphic switch and the onset of the pathogenic program. However, the majority of $b$-responsive genes is not directly regulated by the $\mathrm{bE} / \mathrm{bW}$ heterodimer but requires $\mathrm{Rbf} 1$, a Cys2His2 zinc finger transcription factor encoded by one of the few genes directly regulated by $b E / b W$. Rbf 1 , in turn, is required for the induction of bizl, encoding a Cys2His2 zincfinger transcription factor that is involved in the $\mathrm{G} 2$ cell cycle arrest preceding plant penetration, as well as in the induction of appressoria (Flor-Parra et al. 2006; Bakkeren et al. 2008). $\mathrm{bE} / \mathrm{bW}, \mathrm{Rbf} 1$, and Biz1 are independently required for the establishment of the biotrophic phase, and they are all initially expressed prior to plant penetration. Because these transcription factors are also expressed during the in planta stages of development, it is conceivable that they fulfill additional functions at later stages. Recently, we were able to show by means of a temperature-sensitive $\mathrm{bE}$ protein that the $\mathrm{b}$ heterodimer is essential not only to establish the heterodikaryon after mating of two compatible sporidia and to initiate fungal pathogenicity but also to sustain in planta proliferation and ensure sexual reproduction (Wahl et al. 2010).

However, it is also conceivable that the induction of genes that are specifically expressed within the plant, such as the effector genes, must require additional regulatory pathways; of the 47 plant-induced genes organized in the clusters, only 12 showed an altered expression upon the inactivation of the $\mathrm{bE} / \mathrm{bW}$ heterodimer in planta (Wahl et al. 2010).

We have now identified a gene encoding a forkhead transcription factor, foxl, that is specifically induced in planta. Forkhead proteins, which make up a transcription factor family that displays vast functional diversity, are involved in a wide variety of developmental processes (Carlsson and Mahlapuu 2002). U. maydis strains deleted for fox 1 show no altered phenotype during the saprophytic stage and are able to form dikaryotic filaments that subsequently penetrate the plant. However, at later stages, $\Delta$ foxl strains predominantly aggregate within the vascular bundles, tumor development is severely impaired, and spore formation is abolished. We show that foxl is involved in the regulation of various genes encoding for secreted fungal effector proteins. As a consequence, $\Delta$ fox 1 strains trigger a maize defense response reaction. The hyphae become ensheathed in a matrix that eventually prevents further proliferation and the spread of the infection.

\section{RESULTS}

\section{The plant-induced fox 1 gene encodes a forkhead transcription factor required for pathogenic development.}

To identify $U$. maydis genes with potential regulatory functions during pathogenic development, we have employed custom Affymetrix DNA microarrays to assay the expression profile of the solopathogenic $U$. maydis SG200 (almfa2bE1bW2) (Kämper et al. 2006) after plant infection (M. Vranes and J. Kämper, unpublished). SG200 harbors compatible $a$ and $b$ loci and, thus, is capable of infecting the plant independent from cell fusion with a compatible partner, which allows a more synchronized view of the early infection process. We measured the expression profile of SG200 $16 \mathrm{~h}$ after infection, when the cells start to form appressoria but scarcely have penetrated the cuticle, and at 5, 9, and 13 days after plant infection. One of the genes that was identified to be specifically induced in the plant was um01523 (MIPS [Munich Information Cener for Protein Sequences] Ustilago database); it was only weakly expressed in SG200 on the leaf surface but significantly expressed 5 days postinfection (dpi). To confirm the expression

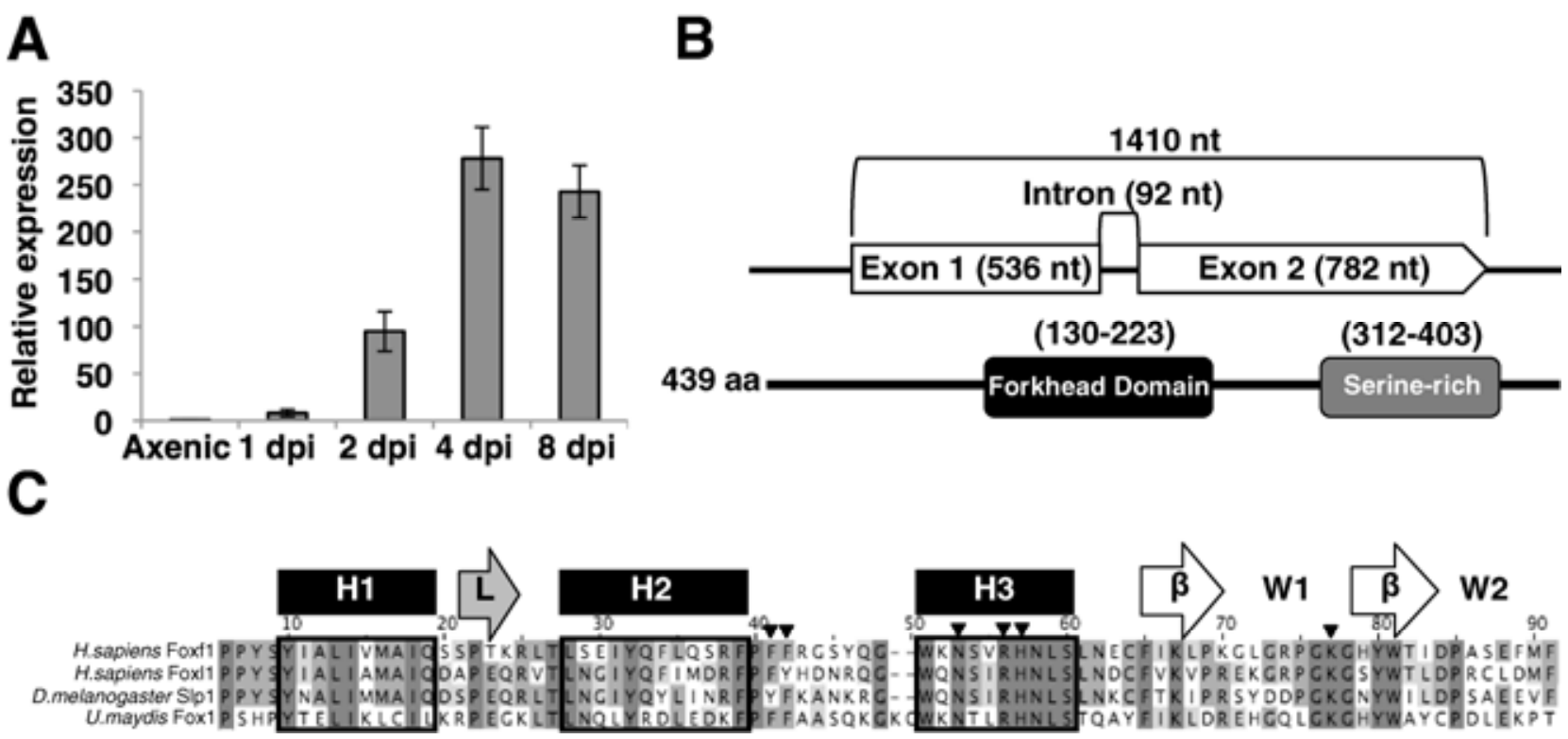

Fig. 1. foxl (um01523) encodes a forkhead protein specifically expressed in planta. A, Expression analysis of fox1. Quantitative reverse transcriptase polymerase chain reaction was used to compare fox 1 expression of the Ustilago maydis solopathogenic strain SG200 in axenic culture (liquid array medium containing $1 \%$ glucose) to the expression in SG200-infected maize leaves 1, 2, 4, and 8 days postinfection. Gene expression values are normalized relative to the constitutively expressed actin gene. Mean expression values are presented relative to the lowest level of expression. Error bars show the standard deviation of mean expression values. B, Schematic presentation of the genomic sequences of fox 1 , including the 92-bp intron, and the predicted protein structure of Fox1. The forkhead domain (amino acids 130 to 223; black box) and a serine-rich region (amino acids 312 to 403 ; gray box) are highlighted. C, Protein sequence alignment of the U. maydis Fox 1 forkhead DNA binding domain (FBD) to FBD of previously described forkhead proteins in Homo sapiens (Foxf1 and Fox11) and Drosophila melanogaster (Slp1). The alignment confirms the presence of a helix-turn-helix core of three $\alpha$-helices (H1, H2, and H3; black boxes) flanked by two wings (W1 and W2). DNA binding sites are highlighted as black arrowheads, three of which are located at residue 3 , 6 , and 7 of the recognition helix (H3). The gray arrow represents a loop (L), and the two white arrows represent $\beta$ sheets. 
profile obtained by the array analysis, we performed quantitative reverse transcriptase polymerase chain reaction (qRTPCR) comparing the expression of um01523 in SG200 cells grown in minimal medium and from SG200 cells in plant tissue at 1, 2, 4, and 8 dpi. Similar to the results obtained by the array analysis, um01523 expression was restricted to the in planta stages (Fig. 1A).

Gene um01523 encodes a protein of 439 amino acids (aa) that harbors i) a domain with similarities to a forkhead DNA binding domain (FBD) (InterPro IPR001766) between residues 130 and 223 and ii) a serine-rich region from residues 312 to 403 (Fig. 1B). Based on the similarities to forkhead proteins, the gene was named foxl. Sequence alignments with previously described forkhead proteins in Homo sapiens and Drosophila melanogaster (Foxf1, Foxl1, and Slp1) supports the presence of a helix-turn-helix core of three $\alpha$-helices $(\mathrm{H} 1$, $\mathrm{H} 2$, and H3) flanked by two wings (W1 and W2) (Fig. 1C). Phylogenetic analysis comparing the protein sequence of Fox 1 to 59 other forkhead proteins places Fox1 within the basidiomycetes, with a more distant evolutionary relationship to ascomycetes and higher eukaryotes, respectively (Supplementary Fig. 1).

The Fox 1 protein is predicted to be nuclear localized (SubLoc v1.0) (reliability index $[\mathrm{RI}]=9$ and expected accuracy $=$ 98\%) (Hua and Sun 2001), which was verified by expression of a Fox1-enhanced green fluorescent protein (eGFP) fusion protein under control of the arabinose-inducible $\mathrm{crg} 1$ promoter (Bottin et al. 1996) in strain FB2 (a2b2) (Fig. 2A). The presence of an FBD domain, the level of conservation of structural motifs within this domain to previously described forkhead proteins, and the nuclear localization suggest that $U$. maydis Fox 1 most likely functions as a transcription factor.
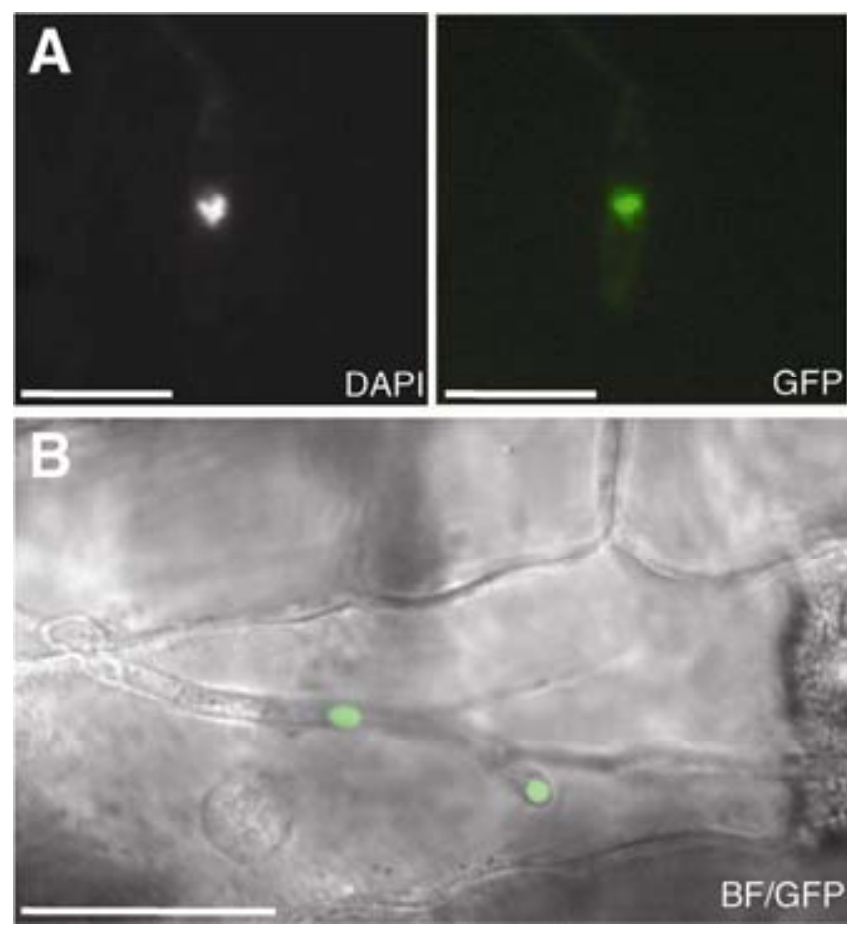

Fig. 2. Fox1 is nuclear localized. A, foxl-inducible strain FB2Pcrgl:foxl: egfp induced for $5 \mathrm{~h}$ in liquid array medium containing $1 \%$ arabinose. Cells were stained with 4',6-diamidino-2-phenylindole (DAPI) (left) to visualize nuclei; the fox 1 :eGFP fusion protein localizes to the nucleus (right). B, Intracellular hypha of the $\Delta$ fox 1 complementation strain $\mathrm{C} 3$ (SG2004fox1 ip ${ }^{r}\left[\right.$ Pfoxl:foxl:egfp]ip ${ }^{s}$ ). Fox1:eGFP is localized to the nucleus of proliferating fungal hyphae during pathogenic development. Microscopic pictures show an overlay of the GFP channel (green) and bright-field projection (gray). Scale bars represent $20 \mu \mathrm{m}$.
To determine the function of Fox1, we deleted the gene in strains FB1 (alb1), FB2 (a2b2), and SG200. In the resulting $\Delta$ foxl strains, we did not observe any alterations with respect to growth rate in minimal medium, morphology, mating, or filament formation (Supplementary Fig. 2). To address whether foxl is involved in pathogenic development, we monitored symptom development of maize plants infected with SG200 $\Delta$ foxl or with a mixture of $\mathrm{FB} 1 \Delta$ foxl $\times \mathrm{FB} 2 \Delta$ foxl in comparison with the respective wild-type control strains. Calcofluor white staining revealed no difference in the frequency of appressoria formation and plant penetration between wild-type strains and the respective $\Delta$ foxl strains, indicating that fox $l$ is not required for plant penetration (data not shown). Until 5 dpi, no differences in symptom development were observed between plants infected by the $\Delta$ fox 1 and wild-type strain. At 7 dpi, however, SG200 $\Delta$ foxl 1 and FB1 $\Delta$ fox $1 \times \mathrm{FB} 2 \Delta$ fox 1 -infected plants showed significantly fewer and, also, smaller tumors; in addition, increased anthocyanin production was evident when compared with their respective wild-type infected plants (Fig. $3 \mathrm{~A}$ and $\mathrm{B}$ ). Quantification of the anthocyanin content (Martin et al. 2002) revealed that $\mathrm{FB} 1 \Delta$ fox $1 \times \mathrm{FB} 2 \Delta$ foxl-infected plants produced substantially more anthocyanin than FB1 $\times$ FB2infected plants (Supplementary Fig. 3). At 14 dpi, tumors of the FB1 $\times$ FB2 infection were filled with black teliospores whereas, in FB1 $\Delta$ fox $1 \times \mathrm{FB} 2 \Delta$ foxl-infected plants, even at 28 dpi, no spore formation was observed (Supplementary Fig. 4).

To demonstrate that the observed mutant phenotype resulted from the foxl deletion, we reintroduced the native foxl gene

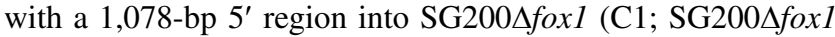
$i p^{r}[$ Pfoxl:foxl $] i p^{s}$ ), which restored the virulence of the resulting strain to wild-type levels (Fig. 3A and B). In addition, we

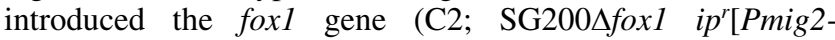
5:foxl] ip ${ }^{s}$ ) and a foxl:eGFP derivative (C3; SG200Afoxl $i p^{r}$ [Pmig2-5:foxl:egfp]ip ${ }^{s}$, both driven by the mig2-5 promoter, which confers high gene expression in planta (Zheng et al. 2008), into SG200 ffoxl. Both constructs were capable of complementing the $\Delta$ foxl mutation (Fig. $3 \mathrm{~A}$ and B). Fluorescence microscopy of plant leaves infected with the $\mathrm{C} 3$ strain verified the nuclear localization of Fox 1 :eGFP in proliferating fungal hyphae during pathogenic development (Fig. 2B).

To determine whether the serine-rich domain is required for Fox 1 function, we replaced the native foxl gene in SG200 with truncated versions of the gene. TR1 encompasses a deletion of the last 79 aa of Fox1 (including the last 43 aa of the serinerich region); in TR2, the entire serine-rich region was deleted and, in TR3, the entire serine-rich region and an additional 89 aa up to the end of the FBD (Supplementary Fig. 5). Plant infections with the different strains revealed that TR1 induced symptoms similar to those of wild-type SG200 infections, while TR2 and TR3 displayed symptoms similar to those of SG200 foxl-infected plants (Fig. 3A andB).

\section{$U$. maydis $\Delta$ fox 1 mutants induce plant defense reactions.}

To examine at which stage of pathogenic development $\Delta$ fox 1 strains were impaired, we performed a more detailed analysis of hyphae during the infection process. Maize leaves infected with $\mathrm{FB} 1 \Delta$ fox $1 \times \mathrm{FB} 2 \Delta$ fox 1 were isolated at 4 and 7 dpi and stained with chlorazole black $E$ to visualize fungal hyphae. At 4 dpi, a significant fraction of the hyphae of the $\Delta$ foxl strains were encased by an optically dense material in the epidermal cells whereas, in infections with wild-type FB1 $\times$ FB2 crosses, such encasements were observed only occasionally. At $7 \mathrm{dpi}$, this phenotype was even more prominent (Fig. 4A through C), with approximately $82 \%$ of FB1 $\Delta$ foxl $\times$ FB $2 \Delta$ foxl-infected epidermal cells containing encased fungal hyphae, compared with approximately $2 \%$ in wild-type infections (Fig. 4D). Staining of FB2 $\Delta$ fox $1 \times$ FB2 $\Delta$ fox 1 -infected leaf tissue with methylene blue 
revealed that the matrix encasing the $\Delta$ foxl hyphae contains cellulose (Fig. 5B and C), indicating that the matrix is generated by the plant cell. In infections with the respective wild-type strains, only the plant cell walls were stained (Fig. 5A). In addition, diaminobenzidine (DAB) staining of $\Delta$ fox 1 -infected plant tissue 2 dpi revealed a very strong accumulation of $\mathrm{H}_{2} \mathrm{O}_{2}$ in and around epidermal cells containing proliferating $\Delta f o x l$ hyphae (Fig. 6B), which was not observed for wild-type hyphae (Fig. 6A). In summary, the data suggest that, unlike wild-type hyphae, $\Delta$ fox 1 hyphae trigger specific defense reactions of the host within the epidermal cells.

Within the plant tissue, FB1 $\times$ FB2 hyphae accumulated around the vascular bundles but were also found frequently in mesophyll cells (Fig. 7A). FB1 1 foxl $\times$ FB2 $\Delta$ foxl hyphae, however, predominantly aggregated within the plant vasculature, and rarely proliferated in the mesophyll (Fig. 7B). More specifically, $\Delta$ foxl hyphae were concentrated in the bundle sheath cells of the vascular bundles (Fig. 7D).

To gain a comprehensive view of the altered plant gene expression in response to infection with $\Delta f o x l$ strains compared with an infection with wild-type strains, we performed microarray analyses on leaf tissue infected with SG2004foxl. In a previous study, the global transcriptional response of the maize plant after infection with SG200 at 12 and $24 \mathrm{~h}$ postinfection and 2, 4, and 8 dpi has been described (Doehlemann et al. 2008a). Using identical experimental conditions, we compared maize plants infected with SG200 foxl to plants infected with SG200 at 4 dpi. The 4-dpi time point was selected due to the initial emergence of encased hyphae.

We used the PageMan software for the identification of biological processes that were significantly overrepresented within the differentially expressed maize genes (Supplementary Fig. 6). We observed an enrichment of downregulated plant genes associated with the metabolism of plant hormones such as auxins and gibberellins and of upregulated genes involved in anthocyanin production; more specifically, the metabolism of phenylpropanoids and flavonoids. In addition, downregulated plant genes involved in cell wall degradation and modification, and upregulated genes involved in cellulose synthesis were over-represented. Within the different categories, several individual genes were at least twofold up- or downregulated (Table 1) (details for filter criteria are given below; significantly regulated genes are summarized in Supplementary Table 1). The downregulation of maize genes involved in the metabolism of auxins and gibberellins, as well as the downregulation of numerous genes involved in cell wall modification and degradation, including seven
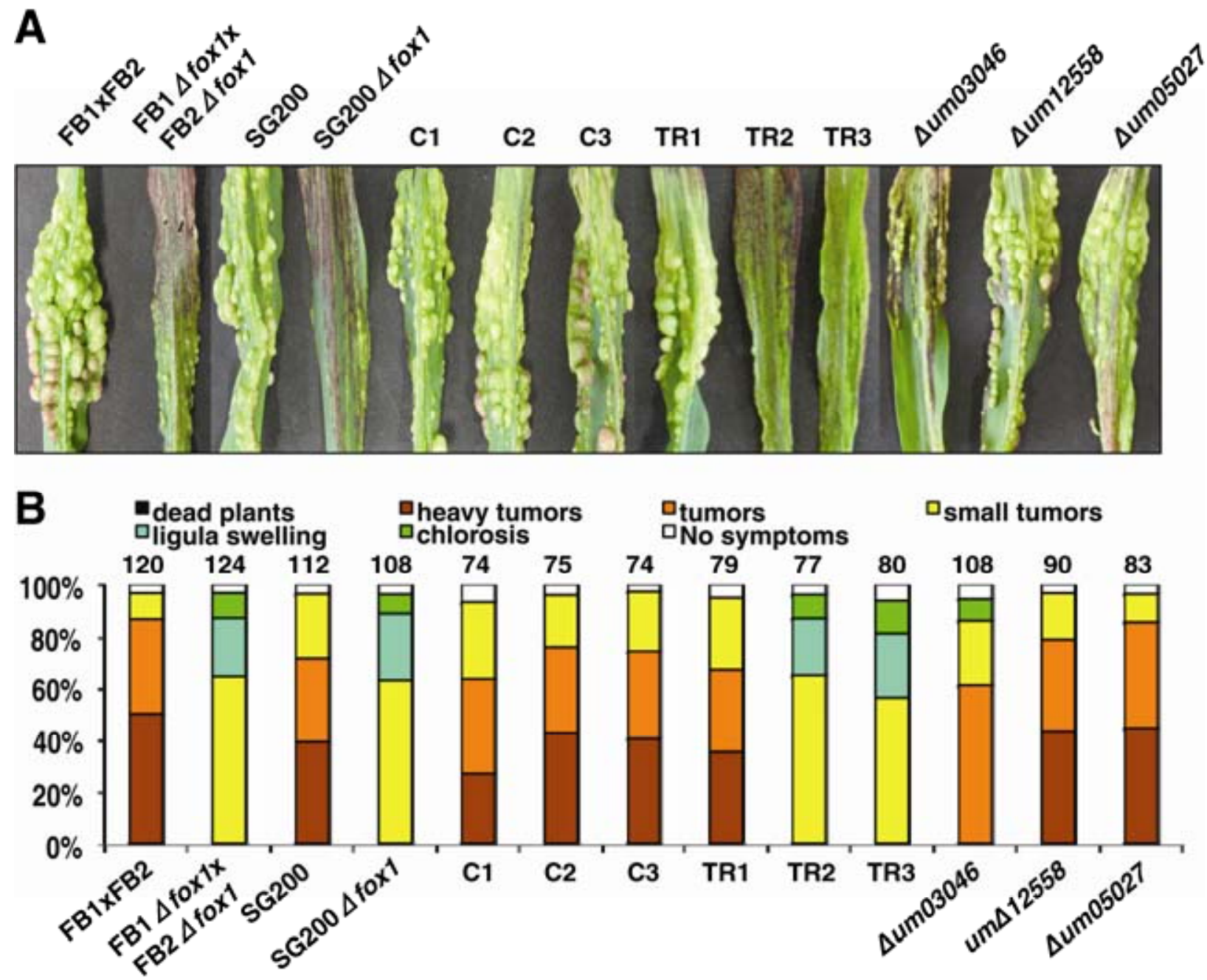

Fig. 3. Fox 1 is required for the biotrophic development of Ustilago maydis. A, Disease symptoms of maize plants 7 days postinfection (dpi) with $U$. maydis strains FB $1 \times$ FB2 (wild-type crosses), FB1 $\Delta$ fox $1 \times$ FB2 $\Delta$ foxl ( $\Delta$ foxl crosses), SG200 (wild-type), SG200 $\Delta$ foxl ( $\Delta$ foxl), $\Delta$ foxl complementation strains C1

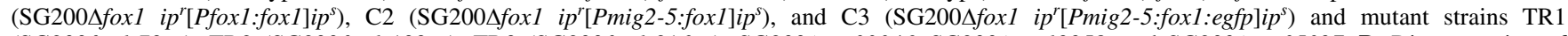

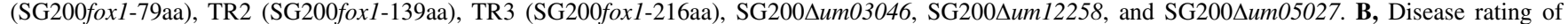

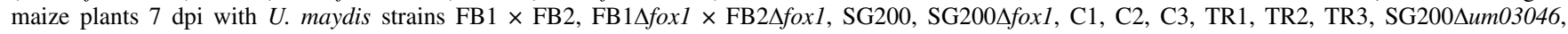

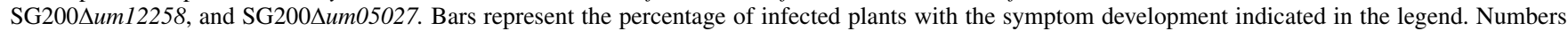
represent the total number of plants infected with the corresponding strain. 
expansins (Table 1), most likely reflects the inability of $\Delta$ foxl strains to induce the formation of tumors. The induction of genes involved in anthocyanin production corroborates the increased anthocyanin content in $\Delta$ foxl-infected leaf tissue (Table 1). Interestingly, we also identified two putative Zea mays cellulose synthase catalytic subunits (ZmCesA11; ZmAffx.13. 1S1_s_at and ZmCesA12; ZmAffx.5.1.S1_at) that were both upregulated (Table 1). Both are prime candidate genes that may be responsible for the synthesis of cellulose forming a constrictive barrier around proliferating $\Delta$ foxl hyphae (Figs. $4 \mathrm{~B}$ and $\mathrm{C}$ and $5 \mathrm{~B}$ and $\mathrm{C}$ ).

\section{Fox1 is involved in the regulation}

of secreted proteins during pathogenic development.

In order to address the function of Fox 1 as a transcriptional activator or repressor and to identify putative target genes of Fox1 in $U$. maydis, we performed microarray analysis using a FB2 derivative harboring the foxl gene under control of the arabinose-inducible $\mathrm{crg} 1$ promoter (FB2Pcrgl:foxl). After $5 \mathrm{~h}$ of growth under inducing conditions, no phenotypic differences between FB2Pcrg1:foxl and the control strain FB2 were observed (Supplementary Fig. 7A and B); the induction of foxl upon medium shift was confirmed by Northern analysis. A custom Affymetrix $U$. maydis array was used to compare the expression profile of FB2Pcrg1:fox 1 and FB2 grown for $5 \mathrm{~h}$ under inducing conditions. The only gene significantly induced was foxl itself (93-fold; data not shown), indicating that Fox1 does not act as a transcriptional regulator under the tested conditions.

Because an altered phenotype of $\Delta f o x l$ strains was observed only during the biotrophic phase of the life cycle, we used the $U$. maydis Affymetrix arrays to compare the expression of $\mathrm{FB} 1 \Delta$ fox 1 and FB2 $\Delta$ fox 1 , and of FB1 and FB2, respectively, 5 dpi of maize plants. This time point was chosen due to the presence of encased $\Delta f o x 1$ hyphae and because it was the earliest time point at which ample fungal material was present in infected leaf tissue for $U$. maydis array detection (data not shown). In total, $141 U$. maydis genes (130 downregulated and 11 upregulated; Supplementary Table 2) were identified that showed a significantly altered expression (greater than twofold, corrected $P$ value $<0.01$ ). Enrichment analysis did not reveal an overrepresentation of functional categories. However, we noticed several $U$. maydis genes encoding proteins involved in sugar processing and transport that were downregulated in the $\Delta$ foxl arrays, among these a glucoamylase precursor (um04064; -21.5-fold), a trehalase precursor (um02212; -4.1fold), an invertase (um01945; -2.9-fold), and a putative glucose transporter (um06076; -2.4-fold). Interestingly, 38 of the differentially expressed $U$. maydis genes encode for proteins predicted to be secreted (33 downregulated and five upregulated), which presented an enrichment from approximately $13 \%$ (expected) to approximately $27 \%\left(P\right.$ value $=4.86 \times 10^{-6}$; normalized to the total number of genes for secreted proteins detectable under the
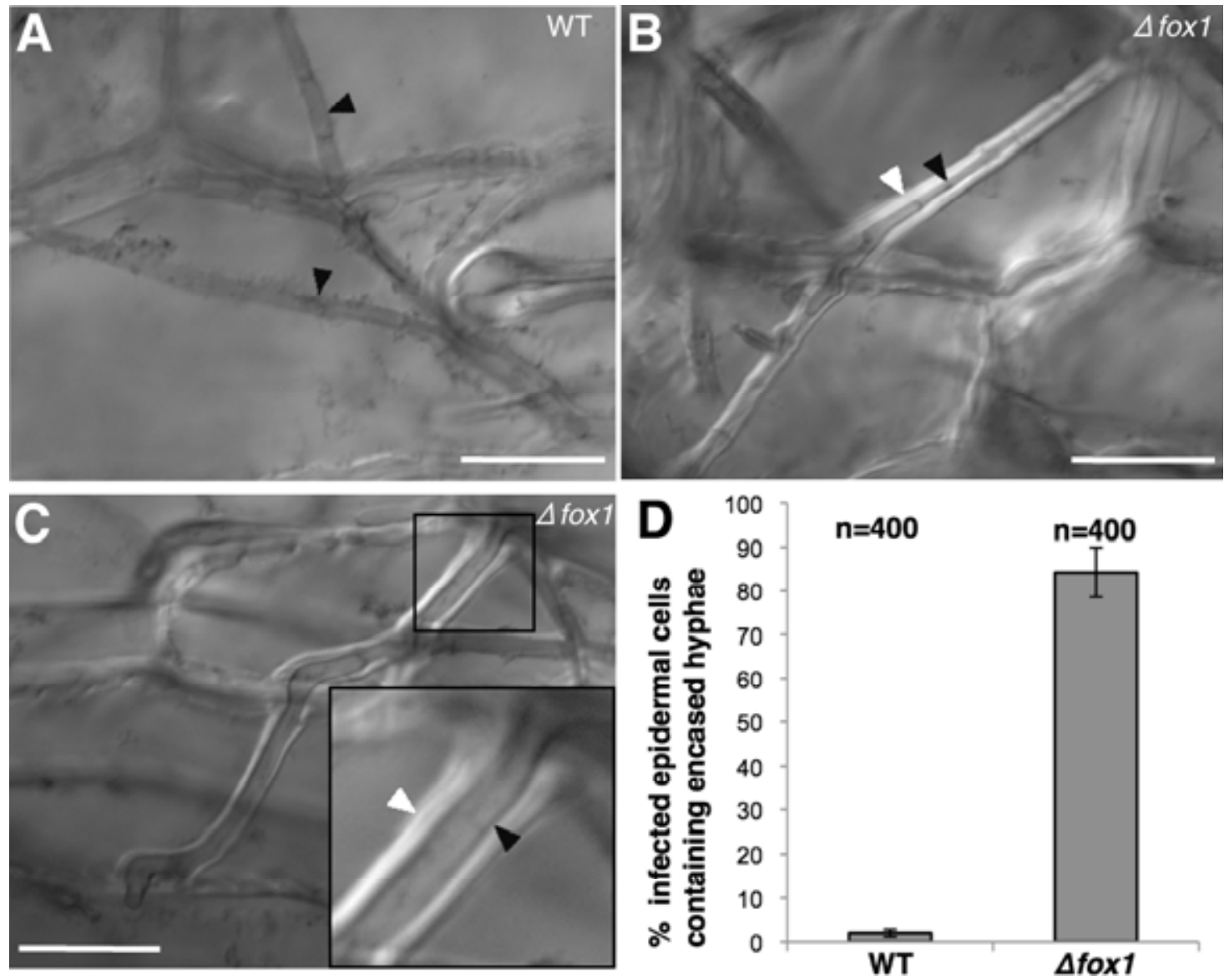

Fig. 4. FB $1 \Delta$ fox $1 \times$ FB2 $\Delta$ foxl 1 induce a defense reaction of the maize plant during pathogenic development. $\mathbf{A}$ and $\mathbf{B}$, Top view of maize leaves 7 days postinfection (dpi) with A, FB1 $\times$ FB2 (wild type [WT]) and B, FB1 $\operatorname{A}$ fox $1 \times \mathrm{FB} 2 \Delta$ foxl $(\Delta$ fox 1$)$ strains, respectively. The barrier encasing FB1 $\Delta$ fox $1 \times$ FB2 $\Delta$ fox 1 hyphae is evident when compared with FB1 $\times$ FB2 hyphae. C, Magnified view of a FB1 1 fox $1 \times$ FB2 $\Delta$ fox 1 hypha proliferating within the epidermal layer. Black arrowhead points to the hypha and white arrowhead to the plant-produced barrier, which appears to be an extension of the plant cell wall. Fungal hyphae were visualized with chlorazole Black E. Scale bars represent $20 \mu \mathrm{m}$. D, Bar graph comparing the percentage of FB1 $\Delta$ fox $1 \times$ FB $2 \Delta$ fox 1 infected and FB1 $\times$ FB2-infected epidermal cells where encased proliferating hyphae can be observed. Infected maize leaves were harvested 7 dpi. In total, eight infected leaves were harvested from eight individual plants and 50 infected epidermal cells were monitored from each sample, for a total of 400 cells. Number above each bar represents the number of infected epidermal cells observed. Error bars are indicated. 
experimental conditions). Notably, we also observed the downregulation of several genes from the phenylpropanoid pathway as a phenylalanine ammonia-lyase (um00078; -5.9-fold), 4-coumarate-CoA ligase (um01171; -14.3-fold), 4-coumarate-CoA ligase 1 (um06153; -8.1-fold), chorismate mutase (um04220; -4.6-fold), and chorismate synthase (um11329; -3-fold).

To identify the $U$. maydis genes that may account for the phenotype of $\Delta$ foxl hyphae during in planta development, the three most downregulated genes encoding secreted proteinsum03046 (-105.1-fold), um12258 (-85.1-fold), and um05027 ( -59.6 -fold) - were deleted in the SG200 background, and the respective deletion strains were assayed for pathogenicity.

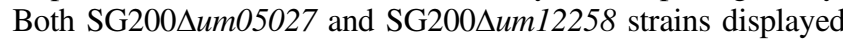
disease ratings similar to SG200, while SG200வum03046 showed a slight reduction in virulence (Fig. 3A and B). For all deletion strains, the microscopic analysis of infected leaf tissues revealed no phenotypic abnormalities in hyphal proliferation. Also, staining with DAB did not reveal increased $\mathrm{H}_{2} \mathrm{O}_{2}$ accumulation when compared with SG200 (data not shown).

Six of the $U$. maydis genes downregulated in response to the foxl deletion encode for potential secreted effectors that belong to three of the clusters that have been linked to pathogenic development (Kämper et al. 2006): um02533 (-5.7-fold) in cluster 6A, um03751 (-6.4-fold), and um03752 (-8.5-fold) in cluster 10A, as well as um05308 (-3.8-fold), um05312 (-4.4fold), and um05314 ( -4.3 -fold) in cluster 19A. It may be conceivable that the simultaneous foxl-dependent deregulation of several genes with functions during pathogenic development, including the genes in these three clusters, contributes to the reduced virulence of $\Delta$ foxl hyphae.

\section{DISCUSSION}

In this study, we have identified the forkhead transcription factor Fox 1 that is specifically expressed during the biotrophic phase of $U$. maydis. Fox 1 is required for full virulence and the attenuation of host defenses.

Fox 1 most likely functions as a transcriptional regulator, because i) the protein harbors a conserved FBD that was shown to confer sequence-specific binding in related proteins from higher eukaryotes (Overdier et al. 1994; Pierrou et al. 1994; Kaufmann et al. 1995) and ii) a Fox 1:eGFP fusion protein localizes specifically to the nucleus. The plant-specific expression profile and the lack of any observable phenotype in axenic culture upon ectopic foxl expression or deletion argue that Fox 1 is involved in the regulation of genes specifically required during the biotrophic stage of $U$. maydis. The plant-specific expression of fox 1 is independent from the $b$-mating-type locus which, in general, is required for the onset of the biotrophic phase. The $\mathrm{bE} / \mathrm{bW}$ heterodimer is neither sufficient to induce fox 1 expression in axenic culture nor required for fox 1 expression during in planta growth: fox 1 is only moderately (-2.5-fold) downregulated in response to inactivation of a temperaturesensitive bE protein in planta (Wahl et al. 2010). Because ectopic expression of Fox1 in axenic culture has no influence on the gene expression profile, we have to assume that, in addition to its transcriptional regulation, Fox1 is regulated via either posttranslational modifications or the interaction with cofactors present only under the specific developmental or environmental conditions within the host plant. A comparable mechanism has been described for the Saccharomyces cerevisiae forkhead protein Fkh2 that is involved in the cell-cycle-dependent transcriptional regulation. Fkh2 binds cooperatively with the MADS-box protein Mcm1 to G2/M-specific promoters; in addition, activation requires the phosphorylation of Fkh2 by the cyclin-dependent kinase $\mathrm{Cdc} 28$, which promotes the interaction of Fkh2 with the coactivator Ndd1 (Spellman et al. 1998; Koranda et al. 2000; Hollenhorst et al. 2001; Darieva et al. 2003, 2006; Reynolds et al. 2003; Pic-Taylor et al. 2004; Pondugula et al. 2009). The mechanisms by which the $U$. maydis Fox1

Table 1. Microarray analysis of Zea mays genes after infection with SG200 $\Delta$ foxl: significantly enriched functional categories

\begin{tabular}{|c|c|c|}
\hline Array probe set & Annotation $^{\mathrm{a}}$ & Fold change $^{b}$ \\
\hline \multicolumn{3}{|l|}{ Cellulose synthesis } \\
\hline ZmAffx.13.1.S1_s_at & Z. mays cellulose synthase catalytic subunit 11 (CesA11) & 3.3 \\
\hline ZmAffx.5.1.S1_at & Z. mays cellulose synthase catalytic subunit 12 (CesA12) & 2.8 \\
\hline \multicolumn{3}{|l|}{ Anthocyanin production } \\
\hline Zm.19108.1.S1_at & (Arabidopsis thaliana) T45624 flavonoid 3-hydroxylase-like protein & 2.8 \\
\hline Zm.3406.1.S1_at & 4CL 4-coumarate coenzyme A ligase & 2.4 \\
\hline \multicolumn{3}{|c|}{ Cell wall modification and degradation } \\
\hline Zm.14507.3.A1_a_at & Z. mays glycosyl hydrolases family 16 protein & -98.4 \\
\hline Zm.13537.1.S1_at & Endoglucanase 1 precursor (endo-1,4- $\beta$-glucanase) & -33.7 \\
\hline Zm.11734.1.A1_a_at & Z. mays polygalacturonase inhibitor 1 & -25.0 \\
\hline Zm.5108.1.A1_at & Z. mays xyloglucan endotransglucosylase/hydrolase protein 23 & -21.7 \\
\hline Zm.13944.3.S1_a_at & Z. mays $\beta$-expansin 8 (expB8) & -20.1 \\
\hline Zm.7152.1.A1_at & Hypothetical protein with pectinesterase activity & -13.4 \\
\hline Zm.11734.2.S1_x_at & Z. mays polygalacturonase inhibitor 1 precursor & -13.0 \\
\hline Zm.5822.1.A1_at & Z. mays $\beta$-expansin 4 (expB4) precursor & -9.5 \\
\hline Zm.6626.1.A1_at & Z. mays polygalacturonase & -8.8 \\
\hline Zm.6419.1.A1_at & Z. mays xyloglucan endotransglucosylase/hydrolase & -7.7 \\
\hline Zm.669.1.S1_at & Z. mays $\alpha$-expansin 5 (expA5) & -6.7 \\
\hline Zm.9565.1.A1_at & Z. mays $\beta$-expansin 3 (expB3) & -6.3 \\
\hline Zm.13728.1.S1_at & Z. mays $\alpha$-expansin 4 (expA4) & -6.2 \\
\hline Zm.1747.1.A1_at & Z. mays $\beta$-expansin 5 (expB5) & -4.7 \\
\hline Zm.665.1.S1_at & Z. mays $\alpha$-expansin $1(\operatorname{expA} 1)$ & -3.9 \\
\hline \multicolumn{3}{|l|}{ Hormone signaling } \\
\hline Zm.5020.1.S1_at & Z. mays IAA12-auxin-responsive Aux/IAA family member & -18.1 \\
\hline Zm.3080.1.A1_at & Z. mays IAA13-auxin-responsive Aux/IAA family member & -4.0 \\
\hline Zm.4896.1.A1_at & Z. mays IAA13-auxin-responsive Aux/IAA family member & -2.2 \\
\hline Zm.10176.1.A1_at & Z. mays gibberellin-regulated protein 1 & -12.6 \\
\hline Zm.8468.1.A1_at & Z. mays gibberellin receptor GID1L2 & -7.0 \\
\hline
\end{tabular}

${ }^{a}$ Gene annotations according to MapMan as described by Doehlemann and associates (2008a and b).

${ }^{\mathrm{b}}$ Fold changes ( $\Delta$ foxl versus wild type) give the relative mean expression of maize plants infected with SG200 $\Delta$ foxl- (4 dpi) compared with the mean expression of maize plants infected with the SG200 wild-type strain (4 dpi) (Doehlemann et al. 2008a and b). Fold changes were calculated using dChip1.3, and values $>2$ and $<-2$ with a corrected $P$ value $<0.001$ were considered to be significant. 
protein is activated still needs to be elucidated; however, the serine-rich region that was shown to be required for Fox 1 function may be a good candidate for an interaction domain.

From the 130 genes that show a foxl-dependent downregulation in planta, 51 genes have previously been shown to be upregulated upon plant infection (Kämper et al. 2006). For example, um03046 is 105-fold reduced in foxl deletion strains and, in wild-type strains, is more than 2,000-fold induced upon
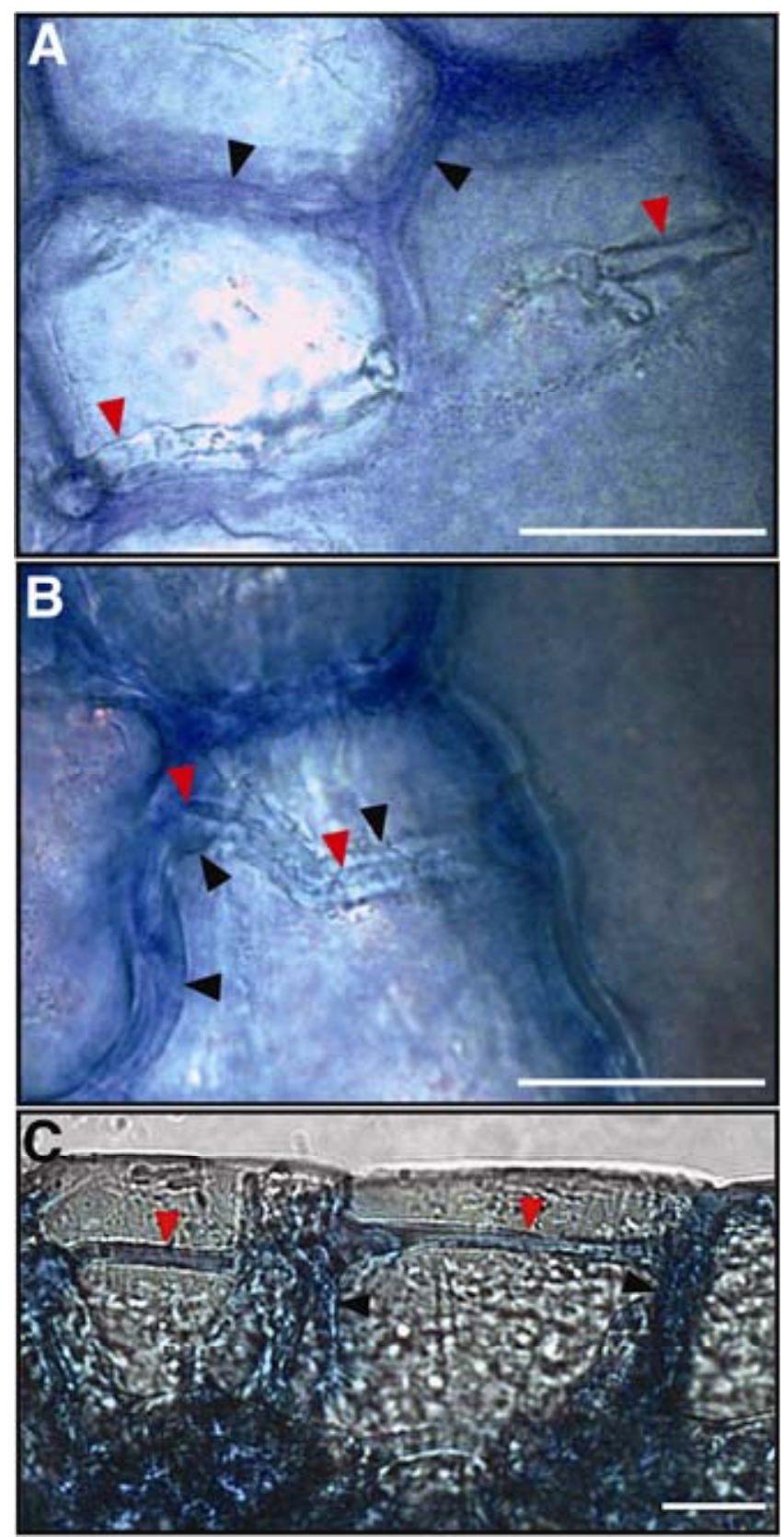

Fig. 5. FB $1 \Delta$ fox $1 \times$ FB $2 \Delta$ fox 1 hyphae are encased in a plant-produced barrier containing cellulose. $\mathbf{A}$ and $\mathbf{B}$, Infected maize leaves 4 days postinfection (dpi). Top view of intracellular proliferating fungal hyphae of Ustilago maydis strains $\mathbf{A}, \mathrm{FB} 1 \times \mathrm{FB} 2$ (wild type $[\mathrm{WT}]$ ) and $\mathbf{B}, \mathrm{FB} 1 \Delta$ fox $1 \times$ FB2 $\Delta$ foxl $(\Delta f o x 1)$. Methylene blue staining was used to visualize cellulose. B, A collapsed proliferating $\Delta$ fox 1 hypha is encased in a plant-produced matrix. Proliferating hyphae are labeled with red arrowheads, and the plant cell walls and matrix are labeled with black arrowheads. C, Methylene-blue-stained cross-sections of an FB1 1 fox $1 \times$ FB2 2 foxl-infected maize leaf 4 dpi. The $\Delta$ foxl hyphae are completely encased, and appear blue in color due to the presence of cellulose in the encasement material. Encased $\Delta$ foxl hyphae are labeled with red arrowheads and the plant cell walls with black arrowheads. Scale bars represent $20 \mu \mathrm{m}$. plant infection. The plant-specific gene regulation of foxlresponsive genes is in accordance with the plant-specific induction and activation of Fox1. However, because a DNA-binding motif for Fox 1 is currently unknown, it remains speculative how many of the foxl-responsive genes are directly regulated by Fox 1 . Interestingly, most of the fox 1 -responsive genes are regulated independently from the $\mathrm{bE} / \mathrm{bW}$ heterodimer, as accessed by the inactivation of a temperature-sensitive $b E$ allele in planta (Wahl et al. 2010). It is conceivable that b-dependent gene regulation is required for the initiation of pathogenic development; after plant penetration, additional regulators such as Fox 1 are then necessary to integrate specific signals and cues to ensure the spatial and temporal gene expression required to maintain the biotrophic interaction.

It is likely that the observed phenotype of the foxl deletion strains in planta is a result of the deregulation of genes required for the adaptation to the host environment, which is corroborated by the finding that several genes coding for potential effectors are regulated by Fox1. The role of effectors as virulence factors in plant-pathogenic fungi and oomycetes is well documented (Birch et al. 2006; Catanzariti et al. 2006; Kamoun 2006, 2007; Kämper et al. 2006; O'Connell and Panstruga 2006b; Morgan and Kamoun 2007), and it is proposed that these effectors play a pivotal role in the interference with host defense and in reprogramming the host to satisfy the needs of the invading pathogen. In $U$. maydis, various genes encoding for potential effectors are arranged in clusters that are specifically induced during biotrophic development, and it has been shown that the deletion of individual clusters affects pathogenic

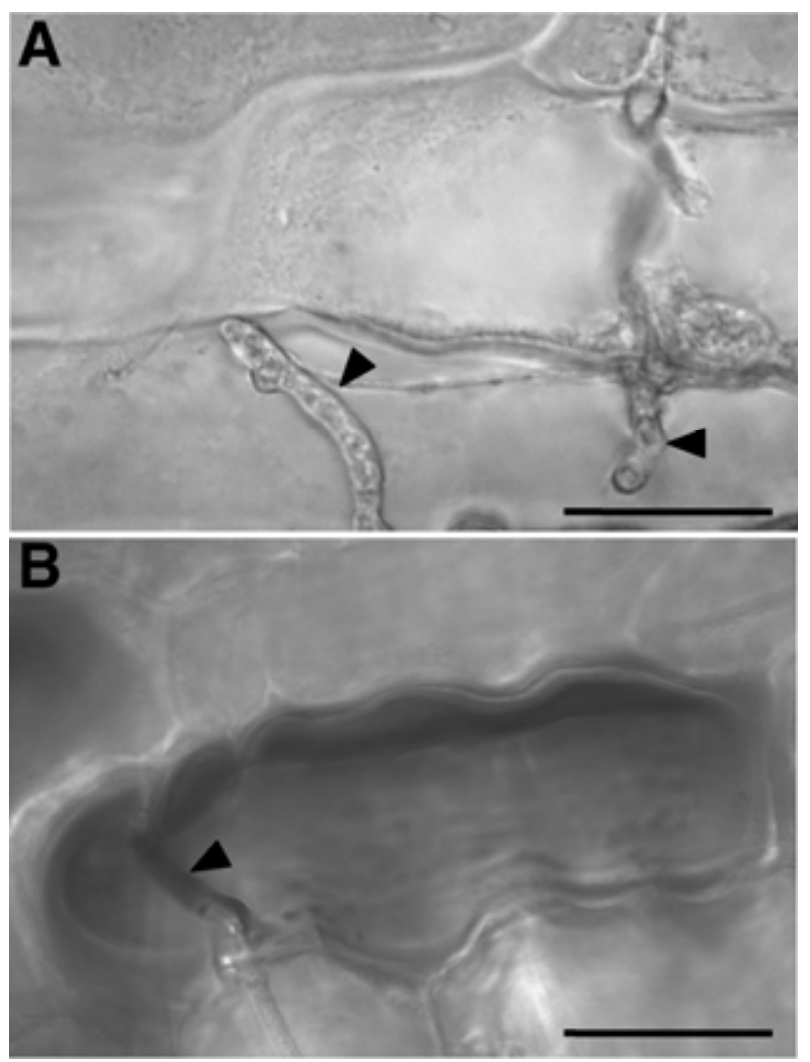

Fig. 6. $\Delta$ foxl hyphae elicit a strong accumulation of $\mathrm{H}_{2} \mathrm{O}_{2}$ in infected epidermal cells. A, SG200 (wild-type) hypha growing in an epidermal cell 2 days postinfection. Diaminobenzidine (DAB) staining was used to visualize $\mathrm{H}_{2} \mathrm{O}_{2}$ accumulation. SG200 does not trigger an $\mathrm{H}_{2} \mathrm{O}_{2}$ response of the plant cells. B, Proliferating SG200 $f$ fox $1(\Delta$ fox 1$)$ hyphae elicit a strong accumulation of $\mathrm{H}_{2} \mathrm{O}_{2}$ in infected and neighboring epidermal cells, represented by a dark stain. Fungal hyphae are labeled with black arrowheads. Scale bars represent $20 \mu \mathrm{m}$. 
development (Kämper et al. 2006). Fox1 is involved in the regulation of six genes in three of the pathogenicity-relevant clusters, three alone in the largest cluster 19A, but also in the regulation of potential effector genes not arranged in clusters. Because Fox 1 affects the regulation of only a fraction of the plant-induced clustered genes, we must postulate additional regulatory circuits. It is conceivable that different effectors must be expressed in temporal and tissue-specific fashion and in response to environmental cues, which most likely involves a complex network of different transcription factors. Individually, the genes regulated by foxl may not be pivotal for biotrophic development but the simultaneous deregulation of several effector genes with potential redundant function is expected to have dramatic impact on virulence. Thus, the single deletion of one of the foxl-dependent effector genes, such as um03046, may lead only to moderately reduced disease symptoms, whereas concerted deregulation together with other effectors may lead to the observed recognition and plant defense reaction.

In addition to the regulation of proteins with potential effector function, we observed the foxl-dependent regulation of several genes from the phenylpropanoid pathway, such as phenylalanine ammonium lyase (PAL), 4-coumarate:coenzyme A ligase, and chorismate mutase. While in plants, the products of this pathway such as flavonoids and anthocyanins with respect to pathogen defense are well documented, their role in fungi has not yet been determined. Although tempting to speculate, we can exclude a detrimental role for pathogenic development, because the deletion of PAL, which conveys the key reaction for the pathway, has no effect (Kim et al. 2001).

Although there is no apparent response of maize plants to infection with wild-type $U$. maydis strains, the infection with foxl deletion strains triggers i) accumulation of reactive oxygen species as $\mathrm{H}_{2} \mathrm{O}_{2}$, ii) accumulation of anthocyanin, and iii) encasement of hyphae in a cellulose-containing matrix. All these reactions can be attributed as defense reactions. The induction and accumulation of $\mathrm{H}_{2} \mathrm{O}_{2}$ and other reactive oxygen species has been shown to act as an intercellular signal resulting in a hypersensitive response, which can lead to the induction of systemic acquired resistance or to programmed cell death (Alvarez et al. 1998; Kuzniak and Urbanek 2000; Talarczyk and Hennig 2001; Mateo et al. 2004) that impedes the spread of biotrophic plant pathogens (Govrin and Levine 2000; Hückelhoven and Kogel 2003). $\mathrm{H}_{2} \mathrm{O}_{2}$ can increase the crosslinking of cell wall proteins, leading to reinforced plant cell walls (Brisson et al. 1994); in addition, $\mathrm{H}_{2} \mathrm{O}_{2}$ has been shown to induce barriers against invading pathogens through the oxidative coupling of feruloyl-polysaccharides in maize cell walls (Encina and Fry 2005). The observed increase in $\mathrm{H}_{2} \mathrm{O}_{2}$ upon $U$. maydis infection could also be explained by the inability of the fungus to detoxify $\mathrm{H}_{2} \mathrm{O}_{2}$, as has been described for $U$. maydis strains deleted for yapl, which encodes a homologue to the $S$. cerevisiae response regulator to oxidative stress (Molina and Kahmann 2007). However, compared with yap1 mutants, DAB staining indicates a drastically higher accumulation of $\mathrm{H}_{2} \mathrm{O}_{2}$ in foxl mutants. In line with the strongly increased $\mathrm{H}_{2} \mathrm{O}_{2}$ concentration is the substantial increase in anthocyanin content in $\Delta$ foxl-infected leaf tissue, which may serve to protect maize cells from oxidative stress (Hipskind et al. 1996). For cotton, it has been suggested that anthocyanins function as antioxidants in response to the hypersensitive response triggered by pathogen attack (Kangatharalingam et al. 2002).

We have shown recently that maize genes involved in auxinsynthesis and -response are transcriptionally induced upon $U$. maydis infection during tumor development (Doehlemann et al. 2008a); in addition, elevated levels of gibberellins has been shown to promote cell elongation (Salas Fernandez et al. 2009). Thus, the observed deregulation of genes involved in hormone response and signaling in $\Delta$ foxl-infected plants can be interpreted as a result of impaired tumor development. In the same line is the observation that several genes encoding expansins were repressed; expansins are essential for plant cell enlargement and numerous developmental processes involved in cell wall modification (Sampedro and Cosgrove 2005). In tomato plants, it has been shown that expansin expression is responding to auxin and gibberellin levels (Caderas et al. 2000); thus, the observed downregulation of the expansin genes in plants infected with $\Delta f o x l$ strains might be attributed to the altered phytohormone levels. Also, the downregulation of several genes involved in the cell wall synthesis and modification, such as xyloglucan endotransglucosylases, a glycosyl hydrolase, an endoglucanase, and a pectinesterase, may reflect the reduced tumor development. Intriguingly, the downregulation of the numerous genes involved in plant cell enlargement stands out against the induction of two genes encoding cellulose synthases (Table 1). It is conceivable that these two genes are not associated with tumor development but may function in a direct response to the invading pathogen. The formation of thick barriers at invasion sites is a well-documented plant response (Hückelhoven 2007). Such barriers are composed of a variety of plant cell wall components, including cellulose, callose, phenolics, pectins, glycoproteins, and thionins (Aist 1976; Snyder and Nicholson 1990; Thordal-Christensen et al. 1997; Bolwell et al. 2002). We observed that the invading hyphae of $\Delta$ foxl strains are encased in a cellulose-containing matrix, which is most likely an extension of the plant cell wall. Comparable cellulose-containing encasements have been observed around the haustoria of Phytophthora parasitica in tobacco (Hanchey and Wheeler 1971). Similar encasements

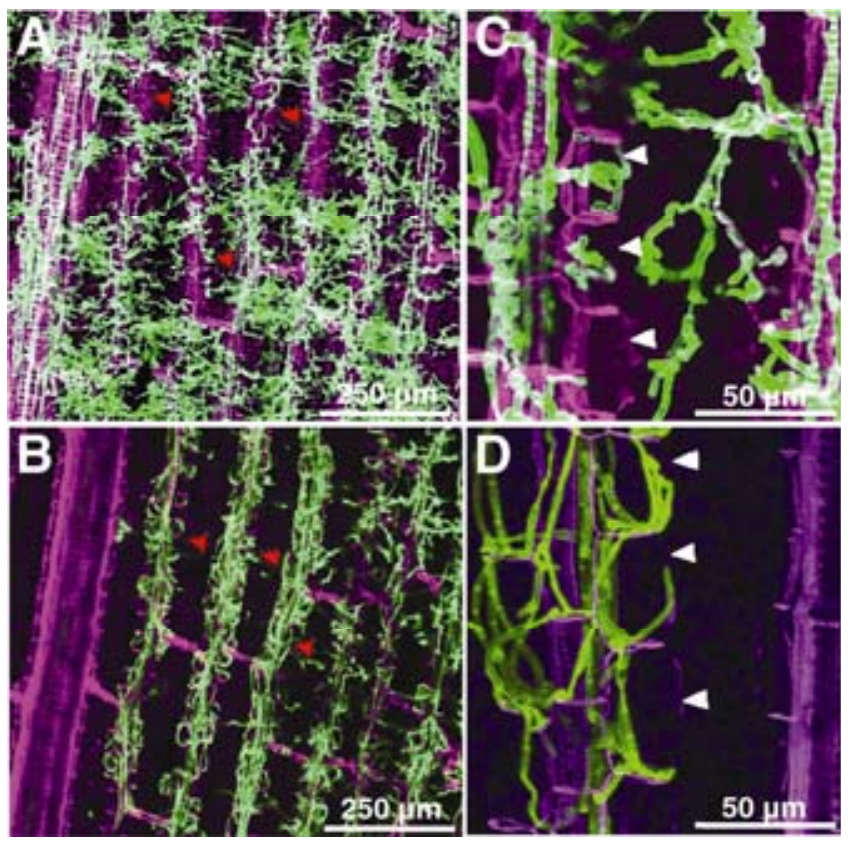

Fig. 7. $\Delta$ foxl hyphae predominantly aggregate within the plant vasculature. A, Top view of a maize leaf infected with FB1 $\times$ FB2 (wild-type [WT]) strains 5 days postinfection (dpi). Fungal hyphae (green) are seen proliferating through the plant mesophyll and vascular bundles (red arrowheads). B, FB $1 \Delta$ fox $1 \times$ FB2 $\Delta$ fox 1 ( $\Delta$ fox 1 )-infected maize leaf 5 dpi. Fungal hyphae are predominantly found growing within the vascular bundles (red arrowheads) and rarely in the mesophyll. C, Magnified view of a maize leaf infected with WT hyphae. D, Magnified view of a maize leaf reveals that $\Delta$ foxl hyphae are mainly concentrated in the bundle sheath (white arrowheads) cells of the vascular bundles. In all images, plant structures appear purple. All images are maximum projection stacks taken with a confocal microscope. 
containing callose were observed in Arabidopsis plants infected with the powdery mildew fungus Golovinomyces orontii (Jacobs et al. 2003), and in an incompatible interaction between Uromyces phaseoli and cowpea; in the latter case, the encasement was linked to the termination of fungal growth (Heath and Heath 1971). In the natural host barley, callose encasements of Blumeria graminis f. sp. hordei haustoria were never observed (Meyer et al. 2009). However, in an incompatible interaction with the nonhost Arabidopsis, nearly all haustoria were partially encased, suggesting the inability of $B$. graminis to suppress the formation of these encasements in an incompatible interaction. In analogy to these systems, the encasement of $\Delta$ foxl hyphae is likely to be interpreted as a plant-induced structural barrier as a defense response.

Previously, three Z. mays cellulose synthases (CesA10 to 12) (Appenzeller et al. 2004) have been implicated in the formation of secondary cell walls due to their similarity to the Arabidopsis CesA family (Turner and Somerville 1997; Taylor et al. 1999, 2000, 2003; Tanaka et al. 2003; Zhong et al. 2003). ZmCesA10 to -12 are predominantly expressed in the maize stalk tissue, with a high abundance of secondary cellulose depositions to reinforce the cell walls and, thus, to increase stalk strength (Appenzeller et al. 2004; Dhugga 2005). We now find ZmCesA11 and ZmCesA12 induced in SG200 $\Delta$ foxl-infected leaf tissue, which argues for a second function of the genes in plant defense (i.e., the deposition of cellulose in response to pathogen attack).

We have observed that $\Delta f o x l$ hyphae predominantly aggregate within the plant vasculature and rarely in the mesophyll. Such a focused growth may be explained by different tissuespecific defense reactions, which may be more severe in the epidermal layer and, in that way, restrict the hyphae to the vasculature. We observed a downregulation of Ustilago maydis genes involved in sugar processing and transport, which may be a secondary effect of the growth in the sugar-rich vascular bundles. However, it is also possible that the focused growth in the plant vasculature is a direct effect of a $\Delta$ foxl-dependent downregulation of genes required for sugar processing and transport.

With Fox1, we have identified the first $b$-independent, plantspecific regulator that is involved in the regulation of a variety of genes that contribute to the establishment of the biotrophic interface of $U$. maydis. The concerted deregulation of foxlregulated genes impedes the delicate adaptation of $U$. maydis to its host plant, which results in the formation of a physical barrier that prevents the proliferation of hyphae as a defense reaction. It will be a future challenge to identify the signaling pathways that lead to foxl induction, and to dissect the foxlresponsive genes and their particular function in avoiding plant defense reactions.

\section{MATERIALS AND METHODS}

Phylogenetic tree construction.

Sequences of Fox1 and 59 forkhead sequences obtained through BlastP were aligned using the MAFFT version 6 global alignment G-INS-I strategy. Six homeodomain protein sequences were used as an outgroup. A phylogenetic tree was generated using the all ungapped neighbor-joining method with a bootstrap value of 1,000. MAFFT results were exported in Nexus format and visualized using FigTree.

\section{Strains and growth conditions.}

$U$. maydis strains were grown in $0.4 \%$ yeast extract, $0.4 \%$ peptone, and $2 \%$ sucrose at $28^{\circ} \mathrm{C}$. Plant infections were performed as described (Kämper et al. 2006). Disease symptoms from infections were scored at $7 \mathrm{dpi}$ as described (Molina and
Kahmann 2007). Mating and filamentation assays were carried out as described previously (Schulz et al. 1990). For induction of fox 1 in axenic culture, strains harboring the fox 1 gene under the control of the arabinose-inducible crgl promoter were grown in liquid array medium $(6.25 \%$ [wt/vol] salt solution [Holliday 1974], $30 \mathrm{mM}$ L-Gln, and 1\% [wt/vol] glucose [pH 7.0], filter sterilized) (Scherer et al. 2006) to an optical density at $600 \mathrm{~nm}$ of 0.5 , washed in $\mathrm{dH}_{2} \mathrm{O}$, and induced in liquid array medium for $5 \mathrm{~h}$ at $28^{\circ} \mathrm{C}$.

All $U$. maydis mutant strains generated in this study were derived from wild-type strains FB1 and FB2, and the solopathogenic strain SG200 (Table 2) (Banuett and Herskowitz 1989; Kämper et al. 2006). Deletion strains for foxl (um01523; GenBank accession no. XP_757670), um03046 (XP_759193), um05027 (XP_761174), and um12258 (XP_760402) were generated using a PCR-based approach (Kämper 2004). Primers for the left and right 1-kb flanking regions and the nested primers for the amplification of the final product after ligation of the left and right border sequences to the hygromycin resistance cassette are given in Supplementary Table 3. Deletion constructs were transformed into the desired background strains as described (Tsukuda et al. 1988). For induced expression of foxl in axenic culture under the control of the crgl promoter, foxl was amplified from cDNA (primers fox1-NdeI-for and fox1-NotI-rev) and incorporated into pRU11 $\Delta$ NotI, a pRU11 (Brachmann et al. 2001) derivative in which the NotI site at position 6,474 has been removed by a fill-in reaction. The resulting construct, pRU11-1c-fox1, was linearized with $S s p$ I and introduced into the ip locus of strains FB2 and AB31 as described by Brachmann and associates (2001). For the induction of foxl:egfp, a 1.3-kb NdeI-SfiI foxl fragment was amplified (primers fox1NdeI-for and fox1-SfiI-rev) and integrated together with a 1-kb eGFP-nosT SfiI-NotI fragment into the respective NdeI-NotI sites of pRU11DNotI, linearized with SspI, and integrated into the ip locus of strain FB2. For complementation analysis using foxl under control of the native foxl promoter, the mig2-5 promoter and egfp were removed from pJF1 (Farfsing et al. 2005) using $X b a \mathrm{I}$ and $A f l \mathrm{II}$ and replaced with foxl and 1,078 bp of the foxl promoter region, generated by PCR amplification using primers fox1-np-XbaI-for and fox1-AflII-rev. To express foxl: egfp under control of the mig2-5 promoter, the fox 1 gene flanked

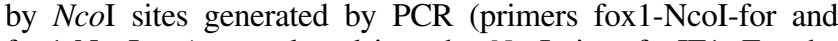
fox1-NcoI-rev) was cloned into the $N c o$ I site of pJF1. For the expression of foxl under mig2-5 control, the 765-bp NcoI-AflII egfp fragment of pJF1 was replaced by a $1.3-\mathrm{kb}$ NcoI-AflII foxl gene generated by PCR (primers fox1-NcoI-for and fox1-AflIIrev). All three complementation constructs were introduced into the ip locus of the strain SG200 foxl; single-copy integration was verified by Southern blot analysis as described (Brachmann et al. 2001). Truncation mutants of the serine-rich region in Fox1 were constructed using the PCR-based approach (Kämper 2004). The same right border was used in all truncation constructs (primers TR-rb-for and TR-rb-rev). Primers for the left borders were as follows: TR1 (fox1-79aa): TR-lb-for and TR1lb-rev; TR2 (foxl-139aa): TR-lb-for and TR2-lb-rev; and TR3 (foxl-216aa): TR-lb-for and TR3-lb-rev. The respective left and right borders were ligated to a $1.9-\mathrm{kb}$ hygromycin resistance cassette with compatible SfiI sites. All three final ligation products were amplified using nested primers TR-nested-for and TRnested-for and transformed into $U$. maydis SG200 as described above. For all strains described, integration was verified by Southern blot analysis.

\section{Staining and microscopy.}

Chlorazole Black staining was performed as described (Brachmann et al. 2003). Hyphae were visualized using an Axio Imager Z1 microscope (Carl Zeiss AG) in the DIC channel 
with AxioVision Rel. 4.7 software (Carl Zeiss AG). $\mathrm{H}_{2} \mathrm{O}_{2}$ accumulation was visualized by DAB staining as previously described (Molina and Kahmann 2007). Plant cells were stained using $0.1 \%$ aqueous methylene blue for $15 \mathrm{~min}$, washed with $\mathrm{dH}_{2} \mathrm{O}$, and visualized by bright-field microscopy. GFP fusion proteins were excited at $488 \mathrm{~nm}$ and emission was detected at 495 to $530 \mathrm{~nm}$. For visualizing hyphae in the plant vasculature, fungal hyphae were stained with Fluorescein WGA (Vector Laboratories). Plant membranes were visualized using propidium iodide (Fluka). Samples were incubated in staining solution (WGA at $10 \mu \mathrm{g} / \mathrm{ml}$, propidium iodide at $1 \mu \mathrm{g} / \mathrm{ml}$, and $0.02 \%$ Tween 20 ) for $15 \mathrm{~min}$ and washed in $1 \times$ phosphate-buffered saline. Confocal images were taken using a TCS-SP5 confocal microscope (Leica) as described (Doehlemann et al. 2009).

\section{Nucleic acid procedures.}

Standard molecular techniques were performed as described (Sambrook et al. 1989). For Southern blot analysis, genomic DNA from $U$. maydis was isolated as described (Schulz et al. 1990). For the microarray experiments of strains induced in axenic culture, total RNA was isolated from three biological replicates using Trizol reagent (Invitrogen) as described by the manufacturer. Northern blot analysis was performed as described (Brachmann et al. 2001). RNA samples to be used in microarray or qRT-PCR were further purified through RNA columns (RNeasy; Qiagen). RNA quality was assessed on a Bioanalyzer with the RNA 6000 Nano LabChip kit (Agilent). For isolation of $U$. maydis RNA from plant material for $U$. maydis microarray analysis, $U$. maydis-infected plants (Early Golden Bantam) were grown in a phytochamber as described (Wahl et al. 2010). Infected plant leaf material from 10 plants was pooled and immediately frozen in liquid nitrogen. RNA was isolated, purified, and assessed as described above. RNA to be used for the Affymetrix Gene ChipR Maize genome arrays was isolated as described (Doehlemann et al. 2008a).

\section{DNA microarrays.}

Affymetrix Gene ChipR Ustilago genome arrays were carried out in three biological replicates using Affymetrix protocols (staining: EukGe2V4 protocol on GeneChip Fluidics Station 400; scanning on Affymetrix GSC3000). Array data was submitted to GeneExpressionOmnibus (GEO: accession GSE19591).
Expression data were analyzed using Affymetrix Micro Array Suite 5.1, R bioconductor software, and dChip1.3 as described (Eichhorn et al. 2006). Probe sets that were present in at least two of three biological replicates were considered expressed. Only genes that displayed fold changes greater than twofold with a difference between expression values $>50$ and a corrected $P$ value $<0.01$ using the FDR algorithm (Benjamini and Hochberg 1995) were considered to be significant. Functional enrichment analysis was carried out using the Blast2Go (Conesa et al. 2005) Fisher's exact test. Enrichment analysis of secreted proteins was done by performing a hypergeometric distribution comparing the total present calls representing secreted proteins on the FB1 $\times$ FB2 in planta arrays to that of the $\mathrm{FB} 1 \Delta$ fox $1 \times \mathrm{FB} 2 \Delta$ foxl in planta arrays. Affymetrix Gene ChipR maize genome arrays were carried out in three biological replicates using RNA isolated from SG2004foxl-infected leaf tissue as described above. Array data were submitted to GEO (accession GSE19559). Array data were analyzed as de-

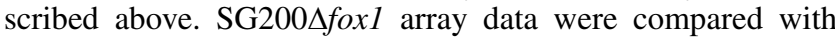
SG200 array data published by Doehlemann and associates (2008a and b). For array data analysis to identify over-represented biological processes, Pageman V 0.11 was used. Subsequently, genes in the enriched biological processes were subjected to more stringent analysis. Genes with expression change greater than twofold, with a difference between expression values $>50$ and a corrected $P$ value $<0.001$, were considered significant.

\section{qRT-PCR.}

Real-time analysis was carried out in three biological replicates, with each biological replicate having its own technical replicate. First-strand synthesis was carried out using SuperScript III (Invitrogen) from $1 \mu \mathrm{g}$ of total RNA. qRT-PCR was performed using a Bio-Rad iCycler along with Platinum SYBR Green qPCR SuperMix-UDG (Invitrogen). Cycling conditions were as follows: $95^{\circ} \mathrm{C}$ for $2 \mathrm{~min}$, followed by 45 cycles of $95^{\circ}$ for $30 \mathrm{~s}, 65^{\circ} \mathrm{C}$ for $30 \mathrm{~s}$, and $72^{\circ} \mathrm{C}$ for $30 \mathrm{~s}$. To verify foxl (um01523) expression, qRT-PCR was performed on RNA isolated from SG200 infected leaf tissue at 1, 2, 4, and $8 \mathrm{dpi}$, and SG200 in axenic culture (liquid array medium: $6.25 \%$ [wt/vol] salt solution, $30 \mathrm{mM} \mathrm{L-Gln}$, and $1 \%$ [wt/vol] glucose, $\mathrm{pH} 7.0$ [filter-sterilized]). Primers used for fox 1 were rt-fox1-for and rt-fox1-rev; for the U. maydis actin (um11232) gene used as a control, primers were rt-actin-for and rt-actinrev (Supplementary Table 3).

Table 2. Ustilago maydis strains used in this study

\begin{tabular}{|c|c|c|}
\hline Strain & Relevant genotype & Reference \\
\hline AB31 & $a 2$ Pcrg:bW2,bE1 & Brachmann et al. (2001) \\
\hline FB1 & al bl & Banuett and Herskowitz (1989) \\
\hline FB2 & $a 2 b 2$ & Banuett and Herskowitz (1989) \\
\hline SG200 & almfa $b W 2 b E 1$ & Bölker et al. (1995) \\
\hline $\mathrm{FB} 1 \Delta$ foxl & al bl $\Delta$ foxl & This study \\
\hline $\mathrm{FB} 2 \Delta$ fox 1 & a 2 b2 $\Delta$ foxl & This study \\
\hline $\mathrm{SG} 200 \Delta$ fox 1 & almfa2 bW2bE1 $\triangle$ foxl & This study \\
\hline FB2Pcrg1:foxl:egfp & a2 b2 ip ${ }^{r}[$ Pcrg1:fox1:egfp $] i p^{s}$ & This study \\
\hline FB2Pcrg1:fox1 & a2 b2 ip ${ }^{r}\left[\right.$ Pcrg1:foxl]ip $p^{s}$ & This study \\
\hline AB31Pcrg1:fox1 & a2 Pcrg:bW2,bE1 ip ${ }^{r}[$ Pcrgl:foxl] $] p^{s}$ & This study \\
\hline SG200fox1:mcherry & almfa2 bW2bE1 foxl:mcherry & This study \\
\hline $\mathrm{C} 1$ & almfa2 bW2bE1 $\triangle$ foxl ip $^{r}\left[\right.$ [Pfoxl:fox1]ip ${ }^{s}$ & This study \\
\hline $\mathrm{C} 2$ & almfa2 bW2bE1 4 fox1 ip $p^{r}\left[\right.$ Pmig2-5:fox1]ip ${ }^{s}$ & This study \\
\hline $\mathrm{C} 3$ & almfa2 bW2bE1 $\Delta f o x 1$ ip ${ }^{r}\left[\right.$ Pmig2-5:fox1:egfp]ip ${ }^{s}$ & This study \\
\hline TR1 & almfa 2 bW2bE1 fox1-79aa & This study \\
\hline TR2 & almfa 2 bW2bE1 fox1-139aa & This study \\
\hline TR3 & almfa 2 bW2bE1 fox $1-216 a a$ & This study \\
\hline 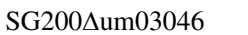 & almfa2 bW2bE1 $\triangle u m 03046$ & This study \\
\hline 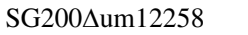 & almfa2 bW2bE1 $\triangle u m 12258$ & This study \\
\hline 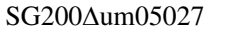 & almfa2 bW2bE1 $\triangle u m 05027$ & This study \\
\hline
\end{tabular}




\section{Anthocyanin measurement.}

Maize plants were infected with FB $1 \Delta$ fox $1 \times \mathrm{FB} 2 \Delta$ fox 1 and FB1 $\times$ FB2 as described above. At 7 dpi, whole plant leaves were harvested in three different pools (eight leaves per falcon tube) and frozen with liquid nitrogen. Anthocyanin extraction and quantification was performed as described (Martin et al. 2002).

\section{ACKNOWLEDGMENTS}

The majority of the experiments presented in this study were designed and performed by A. Zahiri. The initiation of this study is based on experiments designed and performed by K. Heimel. Microarray data were analyzed by A. Zahiri and R. Wahl. Plant cell staining was performed by A. Zahiri and M. Rath. The manuscript was written by A. Zahiri and J. Kämper. We thank R. Kahmann and the Max Planck Institute (MPI) for Terrestrial Microbiology, Marburg, Germany, for generous support; V. Vincon (MPI for Terrestrial Microbiology) for technical assistance; A. Djamei (MPI for Terrestrial Microbiology) for plasmid p123-VCP1; C. Basse (Institute for Applied Biosciences, Karlsruhe Institute of Technology, Germany) for plasmid pJF1; and the International Max-Planck Research School for funding.

\section{LITERATURE CITED}

Aist, J. R. 1976. Papillae and related wound plugs of plant cells. Annu. Rev. Phytopathol. 14:145-163.

Alvarez, M. E., Pennell, R. I., Meijer, P. J., Ishikawa, A., Dixon, R. A., and Lamb, C. 1998. Reactive oxygen intermediates mediate a systemic signal network in the establishment of plant immunity. Cell 92:773-784.

Appenzeller, L., Doblin, M., Barreiro, R., Wang, H., Niu, X., Kollipara, K., Carrigan, L., Tomes, D., Chapman, M., and Dhugga, K.S. 2004. Cellulose synthesis in maize: Isolation and expression analysis of the cellulose synthase (CesA) gene family. Cellulose 11:287-299.

Bakkeren, G., Kamper, J., and Schirawski, J. 2008. Sex in smut fungi: Structure, function and evolution of mating-type complexes. Fungal Genet. Biol. 45 (Suppl. 1):S15-S21.

Banuett, F. 1992. Ustilago maydis, the delightful blight. Trends Genet. 8:174-180.

Banuett, F., and Herskowitz, I. 1989. Different $a$ alleles of Ustilago maydis are necessary for maintenance of filamentous growth but not for meiosis. Proc. Natl. Acad. Sci. U.S.A. 86:5878-5882.

Bauer, R., Oberwinkler, F., and Vanky, K. 1997. Ultrastructural markers and systematics in smut fungi and allied taxa. Can. J. B. 75:1273-1314.

Benjamini, Y., and Hochberg, Y. 1995. Controlling the false discovery rate: A practical and powerful approach to multiple testing. J. R. Stat. Soc. Ser. 57:289-300.

Birch, P. R., Rehmany, A. P., Pritchard, L., Kamoun, S., and Beynon, J. L. 2006. Trafficking arms: Oomycete effectors enter host plant cells. Trends Microbiol. 14:8-11.

Bolwell, G. P., Bindschedler, L. V., Blee, K. A., Butt, V. S., Davies, D. R., Gardner, S. L., Gerrish, C., and Minibayeva, F. 2002. The apoplastic oxidative burst in response to biotic stress in plants: A three-component system. J. Exp. Bot. 53:1367-1376.

Bottin, A., Kämper, J., and Kahmann, R. 1996. Isolation of a carbon source-regulated gene from Ustilago maydis. Mol. Gen. Genet. 253:342-352.

Brachmann, A., Weinzierl, G., Kämper, J., and Kahmann, R. 2001. Identification of genes in the $\mathrm{bW} / \mathrm{bE}$ regulatory cascade in Ustilago maydis. Mol. Microbiol. 42:1047-1063.

Brachmann, A., Schirawski, J., Müller, P., and Kahmann, R. 2003. An unusual MAP kinase is required for efficient penetration of the plant surface by Ustilago maydis. EMBO (Eur. Mol. Biol. Organ.) J. 22:21992210

Brisson, L. F., Tenhaken, R., and Lamb, C. 1994. Function of oxidative cross-linking of cell wall structural proteins in plant disease resistance. Plant Cell 6:1703-1712.

Caderas, D., Muster, M., Vogler, H., Mandel, T., Rose, J. K., McQueenMason, S., and Kuhlemeier, C. 2000. Limited correlation between expansin gene expression and elongation growth rate. Plant Physiol. 123:1399-1414.

Carlsson, P., and Mahlapuu, M. 2002. Forkhead transcription factors: Key players in development and metabolism. Dev. Biol. 250:1-23.

Catanzariti, A. M., Dodds, P. N., Lawrence, G. J., Ayliffe, M. A., and Ellis, J. G. 2006. Haustorially expressed secreted proteins from flax rust are highly enriched for avirulence elicitors. Plant Cell 18:243-256.

Conesa, A., Gotz, S., Garcia-Gomez, J. M., Terol, J., Talon, M., and
Robles, M. 2005. Blast2GO: A universal tool for annotation, visualization and analysis in functional genomics research. Bioinformatics 21:3674-3676.

Darieva, Z., Pic-Taylor, A., Boros, J., Spanos, A., Geymonat, M., Reece, R. J., Sedgwick, S. G., Sharrocks, A. D., and Morgan, B. A. 2003. Cell cycle-regulated transcription through the FHA domain of Fkh2p and the coactivator Ndd1p. Curr. Biol. 13:1740-1745.

Darieva, Z., Bulmer, R., Pic-Taylor, A., Doris, K. S., Geymonat, M., Sedgwick, S. G., Morgan, B. A., and Sharrocks, A. D. 2006. Polo kinase controls cell-cycle-dependent transcription by targeting a coactivator protein. Nature 444:494-498.

Dhugga, K. S. J., Wang, H., Tomes, D., and Helentjaris, T. G. 2005. Maize Cellulose Synthases and Uses Thereof. Pioneer Hi-Bred International, Inc., Johnston, IA, U.S.A.

Doehlemann, G., Wahl, R., Horst, R.J., Voll, L.M., Usadel, B., Poree, F., Stitt, M., Pons-Kuhnemann, J., Sonnewald, U., Kahmann, R., and Kämper, J. 2008a. Reprogramming a maize plant: Transcriptional and metabolic changes induced by the fungal biotroph Ustilago maydis. Plant J. 56:181-195.

Doehlemann, G., Wahl, R., Vranes, M., de Vries, R. P., Kämper, J., and Kahmann, R. 2008b. Establishment of compatibility in the Ustilago maydis/maize pathosystem. J. Plant. Physiol. 165:29-40.

Doehlemann, G., van der Linde, K., Assmann, D., Schwammbach, D. Hof, A., Mohanty, A., Jackson, D., and Kahmann, R. 2009. Pep1, a secreted effector protein of Ustilago maydis, is required for successful invasion of plant cells. PLoS Pathog. 5:e1000290.

Eichhorn, H., Lessing, F., Winterberg, B., Schirawski, J., Kämper, J., Müller, P., and Kahmann, R. 2006. A ferroxidation/permeation iron uptake system is required for virulence in Ustilago maydis. Plant Cell 18:3332-3345.

Encina, A., and Fry, S. C. 2005. Oxidative coupling of a feruloyl-arabinoxylan trisaccharide (FAXX) in the walls of living maize cells requires endogenous hydrogen peroxide and is controlled by a low-Mr apoplastic inhibitor. Planta 223:77-89.

Farfsing, J. W., Auffarth, K., and Basse, C. W. 2005. Identification of cisactive elements in Ustilago maydis mig2 promoters conferring highlevel activity during pathogenic growth in maize. Mol. Plant-Microbe Interact. 18:75-87.

Flor-Parra, I., Vranes, M., Kämper, J., and Perez-Martin, J. 2006. Biz1, a zinc finger protein required for plant invasion by Ustilago maydis, regulates the levels of a mitotic cyclin. Plant Cell 18:2369-2387.

Govrin, E. M., and Levine, A. 2000. The hypersensitive response facilitates plant infection by the necrotrophic pathogen Botrytis cinerea. Curr. Biol. 10:751-757.

Hanchey, P., and Wheeler, H. 1971. Pathological changes in ultrastructure: Tobacco roots infected with Phytophthora parasilica var. nicotianae. Phytopathology 61:33-39.

Heath, M. C., and Heath, I. B. 1971. Ultrastructure of an immune and susceptible reaction of cowpea leaves to rust infection. Physiol. Mol. Plant Pathol. 1:277-287.

Hipskind, J. D., Nicholson, R. L., and Goldsbrough, P. B. 1996. Isolation of a cDNA encoding a novel leucine-rich repeat motif from Sorghum bicolor inoculated with fungi. Mol. Plant-Microbe Interact. 9:819-825.

Hollenhorst, P. C., Pietz, G., and Fox, C. A. 2001. Mechanisms controlling differential promoter-occupancy by the yeast forkhead proteins Fkh1p and Fkh2p: Implications for regulating the cell cycle and differentiation. Genes Dev. 15:2445-2456.

Holliday, R. 1974. Ustilago maydis. Pages 575-595 in: Handbook of Genetics. N. S. Iacobellis, A. Collmer, S. W. Hutcheson, J. W. Mansfield, C. E. Morris, J. Murillo, N. W. Schaad, D. E. Stead, G. Surico, and M. Ullrich, eds. Kluwer Academic Plenum Press, Dordrecht, The Netherlands.

Hua, S., and Sun, Z. 2001. Support vector machine approach for protein subcellular localization prediction. Bioinformatics 17:721-728.

Hückelhoven, R. 2007. Cell wall-associated mechanisms of disease resistance and susceptibility. Annu. Rev. Phytopathol. 45:101-127.

Hückelhoven, R., and Kogel, K. H. 2003. Reactive oxygen intermediates in plant-microbe interactions: Who is who in powdery mildew resistance? Planta 216:891-902.

Jacobs, A. K., Lipka, V., Burton, R. A., Panstruga, R., Strizhov, N., Schulze-Lefert, P., and Fincher, G. B. 2003. An Arabidopsis callose synthase, GSL5, is required for wound and papillary callose formation. Plant Cell 15:2503-2513.

Kamoun, S. 2006. A catalogue of the effector secretome of plant pathogenic oomycetes. Annu. Rev. Phytopathol. 44:41-60.

Kamoun, S. 2007. Groovy times: Filamentous pathogen effectors revealed. Curr. Opin. Plant Biol. 10:358-365.

Kämper, J. 2004. A PCR-based system for highly efficient generation of gene replacement mutants in Ustilago maydis. Mol. Genet. Genomics 271:103-110. 
Kämper, J., Kahmann, R., Bölker, M., Ma, L. J., Brefort, T., Saville, B. J., Banuett, F., Kronstad, J. W., Gold, S. E., Müller, O., Perlin, M. H., Wösten, H. A., de Vries, R., Ruiz-Herrera, J., Reynaga-Pena, C. G., Snetselaar, K., McCann, M., Perez-Martin, J., Feldbrugge, M., Basse, C. W., Steinberg, G., Ibeas, J. I., Holloman, W., Guzman, P., Farman, M., Stajich, J. E., Sentandreu, R., Gonzalez-Prieto, J. M., Kennell, J. C., Molina, L., Schirawski, J., Mendoza-Mendoza, A., Greilinger, D., Münch, K., Rössel, N., Scherer, M., Vranes, M., Ladendorf, O., Vincon, V., Fuchs, U., Sandrock, B., Meng, S., Ho, E. C., Cahill, M. J., Boyce, K. J., Klose, J., Klosterman, S. J., Deelstra, H. J., Ortiz-Castellanos, L., Li, W., Sanchez-Alonso, P., Schreier, P. H., Häuser-Hahn, I., Vaupel, M., Koopmann, E., Friedrich, G., Voss, H., Schlüter, T., Margolis, J., Platt, D., Swimmer, C., Gnirke, A., Chen, F., Vysotskaia, V., Mannhaupt, G., Güldener, U., Münsterkotter, M., Haase, D., Oesterheld, M., Mewes, H. W., Mauceli, E. W., DeCaprio, D., Wade, C. M., Butler, J., Young, S., Jaffe, D. B., Calvo, S., Nusbaum, C., Galagan, J., and Birren, B. W. 2006. Insights from the genome of the biotrophic fungal plant pathogen Ustilago maydis. Nature 444:97-101.

Kangatharalingam, N., Pierce, M. L., Bayles, M. B., and Essenberg, M. 2002. Epidermal anthocyanin production as an indicator of bacterial blight resistance in cotton. Physiol. Mol. Plant Pathol. 61.

Kaufmann, E., Müller, D., and Knochel, W. 1995. DNA recognition site analysis of Xenopus winged helix proteins. J. Mol. Biol. 248:239-254.

Kim, S. H., Virmani, D., Wake, K., MacDonald, K., Kronstad, J. W., and Ellis, B. E. 2001. Cloning and disruption of a phenylalanine ammonialyase gene from Ustilago maydis. Curr. Genet. 40:40-48.

Koranda, M., Schleiffer, A., Endler, L., and Ammerer, G. 2000. Forkheadlike transcription factors recruit Ndd1 to the chromatin of G2/M-specific promoters. Nature 406:94-98.

Kuzniak, E., and Urbanek, H. 2000. The involvement of hydrogen peroxide in plant responses to stresses. Acta Physiol. Plant 22:195-203.

Martin, T., Oswald, O., and Graham, I. A. 2002. Arabidopsis seedling growth, storage lipid mobilization, and photosynthetic gene expression are regulated by carbon:nitrogen availability. Plant. Physiol. 128:472481

Mateo, A., Muhlenbock, P., Rusterucci, C., Chang, C. C., Miszalski, Z., Karpinska, B., Parker, J. E., Mullineaux, P. M., and Karpinski, S. 2004. LESION SIMULATING DISEASE 1 is required for acclimation to conditions that promote excess excitation energy. Plant Physiol. 136:28182830.

Meyer, D., Pajonk, S., Micali, C., O’Connell, R., and Schulze-Lefert, P. 2009. Extracellular transport and integration of plant secretory proteins into pathogen-induced cell wall compartments. Plant J. 57:986-999.

Molina, L., and Kahmann, R. 2007. An Ustilago maydis gene involved in $\mathrm{H}_{2} \mathrm{O}_{2}$ detoxification is required for virulence. Plant Cell 19:2293-2309.

Morgan, W., and Kamoun, S. 2007. RXLR effectors of plant pathogenic oomycetes. Curr. Opin. Microbiol. 10:332-338.

Müller, O., Kahmann, R., Aguilar, G., Trejo-Aguilar, B., Wu, A., and de Vries, R. P. 2008. The secretome of the maize pathogen Ustilago maydis. Fungal Genet. Biol. 45 (Suppl. 1):S63-S70.

O'Connell, R. J., and Panstruga, R. 2006. Tete a tete inside a plant cell: Establishing compatibility between plants and biotrophic fungi and oomycetes. New Phytol. 171:699-718.

Overdier, D. G., Porcella, A., and Costa, R. H. 1994. The DNA-binding specificity of the hepatocyte nuclear factor $3 /$ forkhead domain is influenced by amino-acid residues adjacent to the recognition helix. Mol. Cell. Biol. 14:2755-2766.

Pic-Taylor, A., Darieva, Z., Morgan, B. A., and Sharrocks, A. D. 2004. Regulation of cell cycle-specific gene expression through cyclin-dependent kinase-mediated phosphorylation of the forkhead transcription factor Fkh2p. Mol. Cell Biol. 24:10036-10046.

Pierrou, S., Hellqvist, M., Samuelsson, L., Enerback, S., and Carlsson, P. 1994. Cloning and characterization of seven human forkhead proteins: Binding site specificity and DNA bending. EMBO (Eur. Mol. Biol. Organ.) J. 13:5002-5012.

Pondugula, S., Neef, D. W., Voth, W. P., Darst, R. P., Dhasarathy, A., Reynolds, M. M., Takahata, S., Stillman, D. J., and Kladde, M. P. 2009. Coupling phosphate homeostasis to cell cycle-specific transcription: Mitotic activation of Saccharomyces cerevisiae PHO5 by $\mathrm{Mcm} 1$ and Forkhead proteins. Mol. Cell Biol. 29:4891-4905.

Reynolds, D., Shi, B. J., McLean, C., Katsis, F., Kemp, B., and Dalton, S. 2003. Recruitment of Thr 319-phosphorylated Ndd1p to the FHA domain of Fkh2p requires Clb kinase activity: A mechanism for CLB cluster gene activation. Genes Dev. 17:1789-1802.
Salas Fernandez, M. G., Becraft, P. W., Yin, Y., and Lübberstedt, T. 2009. From dwarves to giants? Plant height manipulation for biomass yield. Trends Plant Sci. 14:454-461.

Sambrook, J., Frisch, E. F., and Maniatis, T. 1989. Molecular Cloning: A Laboratory Manual. Cold Spring Harbor Laboratory Press, Cold Spring Harbor, NY, U.S.A.

Sampedro, J., and Cosgrove, D. J. 2005. The expansin superfamily. Genome Biol. 6:242.

Scherer, M., Heimel, K., Starke, V., and Kämper, J. 2006. The Clp1 protein is required for clamp formation and pathogenic development of Ustilago maydis. Plant Cell 18:2388-2401.

Schulz, B., Banuett, F., Dahl, M., Schlesinger, R., Schäfer, W., Martin, T., Herskowitz, I., and Kahmann, R. 1990. The $b$ alleles of $U$. maydis, whose combinations program pathogenic development, code for polypeptides containing a homeodomain-related motif. Cell 60:295-306.

Snyder, B. A., and Nicholson, R. L. 1990. Synthesis of phytoalexins in Sorghum as a site-specific response to fungal ingress. Science 248:1637-1639.

Spellman, P. T., Sherlock, G., Zhang, M. Q., Iyer, V. R., Anders, K., Eisen, M. B., Brown, P. O., Botstein, D., and Futcher, B. 1998. Comprehensive identification of cell cycle-regulated genes of the yeast Saccharomyces cerevisiae by microarray hybridization. Mol. Biol. Cell 9:3273-3297.

Talarczyk, A., and Hennig, J. 2001. Early defence responses in plants infected with pathogenic organisms. Cell Mol. Biol. Lett. 6:955-970.

Tanaka, K., Murata, K., Yamazaki, M., Onosato, K., Miyao, A., and Hirochika, H. 2003. Three distinct rice cellulose synthase catalytic subunit genes required for cellulose synthesis in the secondary wall. Plant Physiol. 133:73-83.

Taylor, N. G., Scheible, W. R., Cutler, S., Somerville, C. R., and Turner, S. R. 1999. The irregular xylem3 locus of Arabidopsis encodes a cellulose synthase required for secondary cell wall synthesis. Plant Cell 11:769780.

Taylor, N. G., Laurie, S., and Turner, S. R. 2000. Multiple cellulose synthase catalytic subunits are required for cellulose synthesis in Arabidopsis. Plant Cell 12:2529-2540.

Taylor, N. G., Howells, R. M., Huttly, A. K., Vickers, K., and Turner, S. R. 2003. Interactions among three distinct CesA proteins essential for cellulose synthesis. Proc. Natl. Acad. Sci. U.S.A. 100:1450-1455.

Thordal-Christensen, H., Zhang, Z., Wei, Y., and Collinge, D. B. 1997. Subcellular localization of $\mathrm{H}_{2} \mathrm{O}_{2}$ in plants. $\mathrm{H}_{2} \mathrm{O}_{2}$ accumulation in papillae and hypersensitive response during the barley-powdery mildew interaction. Plant J. 11:1187-1194.

Tsukuda, T., Carleton, S., Fotheringham, S., and Holloman, W. K. 1988. Isolation and characterization of an autonomously replicating sequence from Ustilago maydis. Mol. Cell. Biol. 8:3703-3709.

Turner, S. R., and Somerville, C. R. 1997. Collapsed xylem phenotype of Arabidopsis identifies mutants deficient in cellulose deposition in the secondary cell wall. Plant Cell 9:689-701.

Wahl, R., Zahiri, A., and Kämper, J. 2010. The Ustilago maydis b mating type locus controls hyphal proliferation and expression of secreted virulence factors in planta. Mol. Microbiol. 75:208-220.

Zheng, Y., Kief, J., Auffarth, K., Farfsing, J. W., Mahlert, M., Nieto, F., and Basse, C. W. 2008. The Ustilago maydis Cys2His2-type zinc finger transcription factor Mzr1 regulates fungal gene expression during the biotrophic growth stage. Mol. Microbiol. 68:1450-1470.

Zhong, R., Morrison, W. H., 3rd, Freshour, G. D., Hahn, M. G., and Ye, Z. H. 2003. Expression of a mutant form of cellulose synthase AtCesA7 causes dominant negative effect on cellulose biosynthesis. Plant. Physiol. 132:786-795.

\section{AUTHOR-RECOMMENDED INTERNET RESOURCES}

Bioconductor website: www.bioconductor.org

FigTree (a graphical viewer of phylogenetic trees): tree.bio.ed.ac.uk/software/figtree

GeneExpressionOmnibus (GEO) website: www.ncbi.nlm.nih.gov/geo

MAFFT (Multiple alignment program for amino acid or nucleotide sequences) version 6: align.bmr.kyushu-u.ac.jp/mafft/software

Max Planck Institute PageMan Statisitics webpage: mapman.mpimp-golm.mpg.de/pageman/help/help.html\#Statistics MIPS Ustilago database: mips.helmholtz-muenchen.de/genre/proj/ustilago PageMan software V 0.11: mapman.mpimp-golm.mpg.de/pageman Harvard's dChip software webpage: biosun1.harvard.edu/complab/dchip 